Learning In and About Complex Systems

\author{
John D. Sterman
}

WP\# 3660-94-MSA $\quad$ February, 1994 


\title{
Learning In and About Complex Systems
}

\author{
John D. Sterman \\ Sloan School of Management \\ Massachusetts Institute of Technology
}

February 1994

Forthcoming in:

System Dynamics Review

Address correspondence to John Sterman, Sloan School of Management, MIT E53-339, Cambridge MA 02142, or jsterman@mit.edu. This work was supported by the MIT System Dynamics Group and the MIT Organizational Learning Center. 


\begin{abstract}
Change is accelerating, and the complexity of the systems in which we live is growing. Increasingly change is the result of humanity itself. As complexity grows so do the unanticipated side effects of human action, further increasing complexity in a vicious cycle. Many scholars call for the development of 'systems thinking' to improve our ability to manage wisely. But how do people learn in and about complex dynamic systems? Learning is a feedback process in which our decisions alter the real world, we receive information feedback about the world, and using the new information we revise the decisions we make and the mental models that motivate those decisions. Unfortunately, in the world of social action various impediments slow or prevent these learning feedbacks from functioning, allowing erroneous and harmful behaviors and beliefs to persist. The barriers to learning include the dynamic complexity of the systems themselves, inadequate and ambiguous outcome feedback, systematic 'misperceptions of feedback' where our cognitive maps omit important feedback processes, delays, stocks and flows, and nonlinearities that characterize complex systems, inability to simulate mentally the dynamics of our cognitive maps, poor interpersonal and organizational inquiry skills, and poor scientific reasoning skills. To be successful methods to enhance learning about complex systems must address all these impediments. Effective methods for learning in and about complex dynamic systems must include (1) tools to elicit participant knowledge, articulate and reframe perceptions, and create maps of the feedback structure of a problem from those perceptions; (2) simulation tools and management flight simulators to assess the dynamics of those maps and test new policies; and (3) methods to improve scientific reasoning skills, strengthen group process and overcome defensive routines for individuals and teams.
\end{abstract}




\section{Introduction}

The greatest constant of modern times is change. Accelerating changes in technology, population and economic activity are transforming our world, from the prosaic - the effect of information technology on the way we use the telephone - to the profound - the effect of greenhouse gases on the global climate. Some of the changes are desirable, others defile the planet, impoverish the human spirit and threaten our survival. All challenge traditional institutions, practices, and beliefs. Most important, most of the changes we now struggle to comprehend arise as consequences, intended and unintended, of humanity itself.

The dizzying effects of accelerating change are not knew. Henry Adams, a perceptive observer of the great changes wrought by the industrial revolution, formulated a "Law of Acceleration" to describe the exponential growth of technology, production and population that made the legacy of colonial America he inherited irrelevant:

Since 1800 scores of new forces had been discovered; old forces had been raised to higher powers....Complexity had extended itself on immense horizons, and arithmetical ratios were useless for any attempt at accuracy.

...If science were to go on doubling or quadrupling its complexities every ten years, even mathematics should soon succumb. An average mind had succumbed already in 1850; it could no longer understand the problem in 1900. (Adams 1918, pp. 490, 496)

Adams believed the radical changes in society induced by these forces "would require a new social mind." With uncharacteristic, and perhaps ironic, optimism, he concluded "Thus far, since five or ten thousand years, the mind had successfully reacted, and nothing yet proved that it would fail to react - but it would need to jump."

A steady stream of philosophers, scientists, and management gurus have since echoed Adams, lamenting the acceleration and calling for similar leaps to fundamental new ways of thinking and acting. Many advocate the development of 'systems thinking' - the ability to see the world as a complex system, in which we understand that 'you can't just do one thing', that 'everything is connected to everything else'. If people had a holistic world view, it is argued, they would then act in consonance with the long-term best interests of the system as a whole. Indeed, for some, the development of systems thinking is crucial for the survival of humanity.

There are many schools of systems thinking (for surveys, see Richardson 1991 and Lane 1993). Some emphasize qualitative methods, others formal modeling. As sources of method and 
metaphor they draw on fields as diverse as anthropology, biology, engineering, linguistics, psychology, physics and Taoism, and seek applications in fields still more diverse. All agree, however, that a systems view of the world is still rare.

The challenge facing all is how to move from generalizations about accelerating learning and systems thinking to tools and processes that help us understand complexity, design better operating policies and guide organization- and society-wide learning. However, learning about complex systems when you also live in them is difficult. We are all passengers on an aircraft we must not only fly, but redesign in flight. In this paper I review what we know about how people learn in and about complex dynamic systems. Such learning is difficult and rare because a variety of structural impediments thwart the feedback processes required for learning to occur. I argue that successful approaches to learning about complex dynamic systems require (1) tools to articulate and frame issues, elicit knowledge and beliefs, and create maps of the feedback structure of an issue from that knowledge; (2) formal models and simulation methods to assess the dynamics of those maps, test new policies and practice new skills; and (3) methods to sharpen scientific reasoning skills, improve group processes and overcome defensive routines for individuals and teams, that is, in the words of Don Schön (1983a), to raise the quality of the "organizational inquiry that mediates the restructuring of organizational theory-in-use." Systems approaches that fail on any of these dimensions will not prove useful in enhancing the capabilities of individuals or organizations to understand, operate effectively in, nor improve the design of the systems we have created and in which we live, nor can they form the basis for the scientific study of complexity. ${ }^{1}$

\section{Learning is a Feedback Process}

All learning depends on feedback. We make decisions that alter the real world; we receive information feedback about the real world, and using the new information we revise our understanding of the world and the decisions we make to bring the state of the system closer to our goals (figure 1).

The feedback loop in figure 1 appears in many guises throughout the social sciences. George Richardson (1991), in his history of feedback concepts in the social sciences, shows how 
beginning in the 1940s leading thinkers in economics, psychology, sociology, anthropology and other fields recognized that the engineering concept of feedback applied not only to servomechanisms but to human decision making and social settings as well. By 1961, Forrester, in Industrial Dynamics, asserted that all decisions (including learning) take place in the context of feedback loops. Later, Powers (1973, p. 351) wrote:

Feedback is such an all-pervasive and fundamental aspect of behavior that it is as invisible as the air that we breathe. Quite literally it is behavior - we know nothing of our own behavior but the feedback effects of our own outputs. To behave is to control perception.

These feedback thinkers followed in the footsteps of John Dewey, who recognized the feedback loop character of learning around the turn of the century when he described learning as an iterative cycle of invention, observation, reflection and action (Schön 1992). Explicit feedback accounts of behavior and learning have now permeated most of the social and management sciences. Learning as an explicit feedback process has even appeared in practical management tools such as Total Quality Management, where the so-called Shewhart-Deming PDCA cycle (Plan-Do-Check-Act) lies at the heart of the improvement process in TQM (Shewhart 1939, Walton 1986, Shiba, Graham, and Walden 1993).

The single feedback loop shown in figure 1 describes the most basic type of learning. The loop is a classical negative feedback whereby decision makers compare information about the state of the real world to various goals, perceive discrepancies between desired and actual states, and take actions that (they believe will) cause the real world to move towards the desired state. Even if the initial choices of the decision makers do not close the gaps between desired and actual states, the system might eventually reach the desired state as subsequent decisions are revised in light of the feedback received (see Hogarth 1981). When driving, I may turn the steering wheel too little to bring the car back to the center of my lane, but as visual feedback reveals the error, I continue to turn the wheel until the car returns to the straight and narrow. If the current price for products of my firm is too low to balance orders with production, depleted inventories and long delivery delays cause me to gradually raise price until I discover a price that clears the market. ${ }^{2}$

The feedback loop shown in figure 1 obscures an important aspect of the learning process. Information feedback about the real world is not the only input to our decisions. Decisions are the result of applying a decision rule or policy to information about the world as we perceive it 
(see Forrester 1961, 1992). The policies are themselves conditioned by institutional structures, organizational strategies and cultural norms. These, in turn, are governed by the mental models of the real world we hold (figure 2). As long as the mental models remain unchanged, the feedback loop represented in the figure represents what Argyris (1985) calls single loop learning, a process whereby we learn to reach our current goals in the context of our existing mental models. Single loop learning does not result in deep change to our mental models - our understanding of the causal structure of the system, the boundary we draw around the system, the time horizon we consider relevant, nor our goals and values. Single loop learning does not alter our world view.

Mental models are widely discussed in psychology and philosophy. Different theorists describe mental models as collections of routines, scripts or schemata for selecting possible actions, cognitive maps of a domain, typologies for categorizing experience, pointers from instances of a phenomenon to analogous instances, logical structures for the interpretation of language, or attributions about individuals we encounter in daily life (Axelrod 1976, Bower and Morrow 1990, Cheng and Nisbett 1985, Gentner and Stevens 1983, Halford 1993, Johnson-Laird 1983, Schank and Abelson 1977, Vennix 1990). The concept of the mental model has been central to system dynamics from the beginning of the field. Forrester (1961) stresses that all decisions are based on models, and provides a typology classifying models between formal or mental, analytic or simulation, and so forth. In system dynamics, 'mental model' stresses the implicit causal maps of a system we hold, our beliefs about the network of causes and effects that describe how a system operates, along with the boundary of the model (the exogenous variables) and the time horizon we consider relevant - our framing or articulation of a problem.

Most people do not appreciate the ubiquity and invisibility of mental models, instead believing naively that their senses reveal the world as it is. On the contrary, our world is actively constructed - modeled - by our sensory and cognitive structures. Figure 3 shows a Kanizsa triangle, after the Yugoslav psychologist Gaetano Kanizsa. The vast majority of people see a white triangle whose corners cover part of three dark circles and whose body rests on top of a second triangle with black edges. The illusion is extremely powerful. Recent research shows that the neural structures responsible for the ability to 'see' illusory contours such as the white triangle exist between the optic nerve and the areas of the brain responsible for processing visual 
information. ${ }^{3}$ Active modeling occurs well before sensory information reaches the areas of the brain responsible for conscious thought. Powerful evolutionary pressures are responsible: our survival depends so completely on the ability to rapidly interpret reality that we (and other species) long ago evolved structures to build these models automatically. Usually we are totally unaware these mental models even exist. It is only when a construction such as the Kanizsa triangle reveals the illusion that we become aware of our mental models. ${ }^{4}$

The Kanizsa triangle illustrates the necessity of active and unconscious mental modeling or construction of 'reality' at the level of visual perception. Modeling of higher-level knowledge is likewise unavoidable and often equally unconscious. Figure 4 shows a mental model elicited during a meeting between my colleague Fred Kofman and a team from a large global corporation. The company worked with the Organizational Learning Center at MIT to explore ways to reduce the total cycle time for their supply chain. At that time the cycle time was 182 days and they sought to reduce it by half, to 90 days. The company viewed reductions in cycle time as essential for continued competitiveness and even corporate survival. With the support of senior management, they assembled a team to address these issues. At the first meeting the team presented background information, including figure 4 . The figure shows the current cycle time divided into three intervals along a line: manufacturing lead time; order fulfillment lead time; and customer acceptance lead time. Order fulfillment, which then required 22 days, occupies more than half of the total length of the line, while the manufacturing lead time, then requiring 75 days (70 days due to suppliers), receives about one quarter of the length. Customer acceptance, then requiring 85 days, occupies only about one eighth of the total length. What the figure reveals is the prominence of order fulfillment operations in the mental models of the people on the team and the insignificance in their minds of vendors and customers. It will come as no surprise to the reader that the members of the team all worked in functions contributing to order fulfillment. There was not a single person at the meeting representing procurement, nor a single supplier representative, nor anyone from accounting, nor a single customer. Until Fred pointed out this distortion, the members of the group were as unaware of the illusory character of their image of the supply line as we normally are of the illusory contours we project onto the sense data transmitted by our optic nerves. The distorted mental model of the supply chain significantly 
constrained the company's ability to achieve cycle time reduction: even if order fulfillment could be accomplished instantly the organization would fall well short of its cycle time goal.

The type of reframing stimulated by Fred's intervention, denoted 'double loop learning' by Argyris (1985), is illustrated in figure 5. Here information feedback about the real world not only alters our decisions within the context of existing frames and decision rules but feeds back to alter our mental models. As our mental models change we create different decision rules and change the strategy and structure of our organizations. The same information, filtered and processed through a different decision rule, now yields a different decision. The development of systems thinking is a double-loop learning process in which we replace a reductionist, partial, narrow, short-term view of the world with a holistic, broad, long-term, dynamic view - and then redesign our policies and institutions accordingly.

\section{Barriers to Learning}

For learning to occur each link in the two feedback loops must work effectively and we must be able to cycle around the loops quickly relative to the rate at which changes in the real world render existing knowledge obsolete. Yet in the real world, particularly the world of social action, these feedbacks often do not operate well. Figure 6 shows the main ways in which each link in the learning feedbacks can fail. These include dynamic complexity, imperfect information about the state of the real world, confounding and ambiguous variables, poor scientific reasoning skills, defensive routines and other barriers to effective group processes, implementation failure, and the misperceptions of feedback that hinder our ability to understand the structure and dynamics of complex systems.

3.1 Dynamic Complexity: Much of the literature in psychology and other fields suggests learning proceeds via the simple negative feedback loops described in figure 5. Implicitly, the loops are seen as effectively first-order, linear negative feedbacks that produce stable convergence to an equilibrium or optimal outcome. The real world is not so simple. From the beginning, system dynamics emphasized the multi-loop, multi-state, nonlinear character of the feedback systems in which we live (Forrester 1961). The decisions of any one agent form but one of many feedback loops that operate in any given system. These loops may reflect both 
anticipated and unanticipated side effects of the decision maker's actions; there may be positive as well as negative feedback loops; and these loops will contain many stocks (state variables) and many nonlinearities. Natural and human systems have high levels of dynamic complexity.

Time delays between taking a decision and its effects on the state of the system are common and particularly problematic. Most obviously, delays reduce the number of times one can cycle around the learning loop, slowing the ability to accumulate experience, test hypotheses, and improve. Schneiderman (1988) estimated the improvement half life - the time required to cut defects in half - in a wide range of manufacturing firms. He found improvement half lives as short as a few months for processes with short delays, for example reducing operator error in a job shop, while complex processes with long time delays such as product development had improvement half lives of several years or more (Kofman, Repenning and Sterman 1994 show how these differential improvement rates led to difficulty at a leading semiconductor manufacturer).

Dynamic complexity not only slows the learning loop, it reduces the learning gained on each cycle. In many cases controlled experiments are prohibitively costly or unethical. More often, it is simply impossible to conduct controlled experiments. Complex systems are in disequilibrium and evolve. Many actions yield irreversible consequences. The past cannot be compared well to current circumstance. The existence of multiple interacting feedbacks means it is difficult to hold other aspects of the system constant to isolate the effect of the variable of interest; as a result many variables simultaneously change, confounding the interpretation of changes in system behavior (see below), and reducing the effectiveness of each cycle around the learning loop.

Delays also create instability in dynamic systems. Adding time delays to the negative feedback loops increases the tendency for the system to oscillate. ${ }^{5}$ Systems from driving a car to drinking alcohol to raising hogs to construction of office buildings all involve time delays between the initiation of a control action (accelerating/braking, deciding to 'have another', choosing to breed more hogs, initiating development of a new building) and its effects on the state of the system. As a result, decision makers often continue to intervene to correct apparent discrepancies between the desired and actual state of the system even after sufficient corrective actions have been taken to restore the system to equilibrium, leading to overshoot and oscillation. The result 
is stop-and-go traffic, drunkenness, commodity cycles, and real estate boom-and-bust cycles (see Sterman 1989a for discussion). Oscillation and instability reduce our ability to control for confounding variables and discern cause and effect, further slowing the rate of learning.

3.2 Limited Information: We experience the real world through filters. No one knows the current sales rate of their firm, the current rate of production or the true value of the order back$\log$ at any given time. Instead we receive estimates of these data, based on sampled, averaged, and delayed measurements. The act of measurement introduces distortions, delays, biases, errors and other imperfections, some known, others unknown and unknowable. Above all, measurement is an act of selection. Our senses and information systems select but a tiny fraction of possible experience. Some of the selection is 'hard-wired' (we cannot see in the infrared or hear ultrasound). Some results from our own decisions. We define gross domestic product so that extraction of nonrenewable resources counts as production of 'goods' rather than depletion of natural capital stocks, and so that medical care to treat pollution-induced disease is counted as goods and services that add to GDP while the production of the pollution itself does not reduce it. Because the prices of most goods in our economic system do not include the costs of resource depletion or waste disposal, these 'externalities' receive little weight in decision making (see Cobb and Daly 1989 for thoughtful discussion of alternative measures of economic welfare).

Of course, the information systems governing the feedback we receive and its characteristics can change as we learn. They are part of the feedback structure of our systems. Through our mental models we define constructs such as 'GDP' or 'scientific research', create metrics for these constructs, and design information systems to evaluate and report them. These then condition the perceptions we form. Changes in our mental models are constrained by what we previously chose to define, measure, and attend to. Seeing is believing and believing is seeing. 6

In a famous experiment, Bruner and Postman (1949) showed playing cards to people using a tachistoscope to control exposure time to the stimuli. Most subjects could identify the cards rapidly and accurately. They also showed subjects anomalous cards, such as a black three of hearts, or a red ten of spades. Subjects took on average four times as long to judge the anomalous cards. Many misidentified them (e.g. they said 'three of spades' or 'three of hearts' 
when shown a black three of hearts). Some could not identify the card at all, even with very long exposure times, and grew anxious and confused. Only a small minority correctly identified the cards. Bruner and Postman concluded "Perceptual organization is powerfully determined by expectations built upon past commerce with the environment." The self-reinforcing feedback between expectations and perceptions has been repeatedly demonstrated in a wide variety of experimental studies (see Plous 1993 for excellent discussion). Sometimes the positive feedback assists learning by sharpening our ability to perceive features of the environment, as when an experienced naturalist identifies a bird in a distant bush where the novice birder sees only a tangled thicket. Often, however, the mutual feedback of expectations and perception limits learning by blinding us to the anomalies that might challenge our mental models. Thomas Kuhn (1970) cited the Bruner-Postman study to argue that a scientific paradigm suppresses the perception of data inconsistent with the paradigm, making it hard for scientists to perceive anomalies that might lead to scientific revolution. Sterman (1985) developed a formal model of Kuhn's theory, which showed the positive feedback between expectations and perceptions suppressed the recognition of anomalies and the emergence of new paradigms.

Two recent cases, one a global environmental issue, the other the fight against AIDS, show the mutual dependence of expectation and perception is no laboratory artifact but a phenomenon with potentially grave consequences for humanity.

The first scientific papers describing the ability of chlorofluorocarbons (CFCs) to destroy atmospheric ozone were published in 1974 (Stolarski and Cicerone 1974, Molina and Rowland 1974). Yet much of the scientific community remained skeptical, and despite a ban on CFCs as aerosol propellants, global production of CFCs remained near its all time high. It was not until 1985 that evidence of a deep 'ozone hole' in the Antarctica was published (Farman, Gardiner and Shanklin 1985). As described by Meadows, Meadows, and Randers (1992, 151-152):

The news reverberated around the scientific world. Scientists at [NASA]...scrambled to check readings on atmospheric ozone made by the Nimbus 7 satellite, measurements that had been taken routinely since 1978. Nimbus 7 had never indicated an ozone hole.

Checking back, NASA scientists found that their computers had been programmed to reject very low ozone readings on the assumption that such low readings must indicate instrument error.

The NASA scientist's belief that low ozone readings must be erroneous led to them to design a 
measurement system that made it impossible to detect low readings that might have invalidated their models. Fortunately, NASA had saved the original, unfiltered data and later confirmed that total ozone had indeed been falling since the launch of Nimbus 7. Because NASA created a measurement system immune to disconfirmation the discovery of the ozone hole and resulting global agreements to cease CFC production were delayed by as much as seven years. Those seven years could be significant: ozone levels in Antarctica dropped to less than one third of normal in 1993, and current models show atmospheric chlorine will not begin to fall until the year 2000, and then only slowly. Recent measurements show thinning of the ozone layer is a global phenomenon, not just a problem for penguins. Measurements taken near Toronto show a $5 \%$ increase in cancer-causing UV-B ultraviolet radiation at ground level: ozone depletion now affects the agriculturally important and heavily populated northern hemisphere .7

The second example comes from the fight against AIDS. Until recently AIDS vaccine research was dominated by the search for 'sterilizing immunity' - a vaccine that could prevent a person from becoming infected with HIV altogether, rather than 'merely' preventing disease. Potential vaccines are administered to monkeys, who are then challenged with SIV, the simian analog of HIV. The blood and lymph systems of the monkeys are then tested to see if they become infected. Despite early promise, the candidate vaccines tried so far have failed: the vaccinated monkeys became infected at about the same rate as the unvaccinated controls. As each trial vaccine failed researchers moved on to other candidates. The experimenters often killed the monkeys from the failed trial to free up lab space for the next trial. A few researchers, however, continued to observe their monkeys. They were surprised to find that even though their vaccine did not prevent infection, the vaccinated monkeys survived longer, were healthier and had lower concentrations of virus in their blood than the controls. These results are stimulating interest in a model of disease prevention rather than prevention of infection. However, evaluation of and thus resources to support work in the new approach have been delayed because so many of the monkeys that received trial vaccinations were killed after blood tests revealed they had become infected, denying the researchers the opportunity to observe whether the vaccine helped prevent AIDS. Patricia Fast, a researcher with the US National Institute on AIDS, lamented "A lot of monkeys have been killed because it seemed like the experiment was over....In retrospect, we 
wish we would have kept them alive" (quoted in Cohen 1993). Just as NASA's belief that ozone concentrations could not be low prevented them from learning that ozone concentrations were low, the belief that only sterilizing immunity could stop AIDS prevented researchers from discovering another promising therapy as early as they might have. ${ }^{8}$

3.3 Confounding variables and ambiguity: To learn we must use the limited and imperfect feedback available to us to understand the effects of our own decisions, so we can adjust our decisions to align the state of the system with our goals (single loop learning) and so we can revise our mental models and redesign the system itself (double loop learning). Yet much of the outcome feedback we receive is ambiguous. Ambiguity arises because changes in the state of the system resulting from our own decisions are confounded with simultaneous changes in a host of other variables, both exogenous and endogenous. The number of variables that might affect the system vastly overwhelms the data available to rule out alternative theories and competing interpretations. This 'identification problem' plagues both qualitative and quantitative approaches. In the qualitative realm, ambiguity arises from the ability of language to support multiple meanings. In the opening soliloquy of Richard III, the hump-backed Richard laments his deformity:

And therefore, since I cannot prove a lover To entertain these fair well-spoken days, I am determinèd to prove a villain And hate the idle pleasures of these days. $(\mathrm{I}, \mathrm{i}, 28-31)$

Does Richard celebrate his free choice to be evil or resign himself to a predestined fate? Did Shakespeare intend the double meaning? Rich, ambiguous texts, with multiple layers of meaning often make for beautiful and profound art, along with employment for literary critics, but also make it hard to know the minds of others, rule out competing hypotheses, and evaluate the impact of our past actions so we can decide how to act in the future.

In the quantitative realm, econometricians have long struggled with the problem of uniquely identifying the structure and parameters of a system from its observed behavior. Elegant and sophisticated theory exists to delimit the conditions in which one can identify a system. In practice the data are too scarce, and the plausible alternative specifications too numerous for econometric methods to discriminate among competing theories. The same data often support 
wildly divergent models equally well, and conclusions based on such models are not robust. As

Leamer (1983) put it in an article entitled "Let's take the 'con' out of econometrics"

"In order to draw inferences from data as described by econometric texts, it is necessary to make whimsical assumptions....The haphazard way we individually and collectively study the fragility of inferences leaves most of us unconvinced that any inference is believable."9

\subsection{Misperceptions of Feedback: Effective management is difficult in a world of high}

dynamic complexity. Our decisions may create unanticipated side effects and delayed consequences. Our attempts to stabilize the system may destabilize it. Our decisions may provoke reactions by other agents seeking to restore the balance we upset. Our decisions may move the system into a new regime of behavior where unexpected and unfamiliar dynamics arise because the dominant feedback loops have changed. Forrester (1971) calls such phenomena the 'counter-intuitive behavior of social systems'. It often leads to 'policy resistance', the tendency for interventions to be delayed, diluted or defeated by the response of the system to the intervention itself (Meadows 1982). No less an organizational theorist than Machiavelli discussed policy resistance at length, observing in the Discourses that

...when a problem arises either from within a republic or outside it, one brought about either by internal or external reasons, one that has become so great that it begins to make everyone afraid, the safest policy is to delay dealing with it rather than trying to do away with it, because those who try to do away with it almost always increase its strength and accelerate the harm which they feared might come from it. (Machiavelli 1979, 240-241).

Recent experimental studies confirm these observations. Human performance in complex dynamic environments is poor relative to normative standards, and even compared to simple decision rules.

- Subjects, including experienced managers, in a simple production-distribution system (the Beer Distribution Game) generate costly fluctuations, even when consumer demand is constant. Average costs were more than ten times greater than optimal (Sterman 1989b).

- Subjects responsible for capital investment in a simple multiplier-accelerator model of the economy generate large amplitude cycles even though consumer demand is constant. Average costs were more than thirty times greater than optimal (Sterman 1989a).

- Subjects managing a firm in a simulated consumer product market generate the boom and bust, price war, and shake-out characteristic of industries from video games to chain saws (Paich and Sterman 1993). 
- Participants in experimental asset markets repeatedly bid prices well above fundamental value, only to see them plummet when a 'greater fool' can no longer be found to buy. These speculative bubbles do not disappear when the participants are investment professionals, when monetary incentives are provided, or when short-selling is allowed (Smith, Suchanek, and Williams 1988).

- In a forest fire simulation, many people allow their headquarters to burn down despite their best efforts to put out the fire (Brehmer 1989).

- In a medical setting, subjects playing the role of doctors order more tests while the (simulated) patients sicken and die (Kleinmuntz and Thomas 1987).

These studies and many others (Brehmer 1992 provides a recent review; Funke 1991 reviews the large literature of the 'German School' led by Dörner, Funke, and colleagues) show that performance is far from optimal - often far from reasonable - in a wide range of tasks, from managing an ecosystem to governing a town to controlling a factory.

In the 'Beer Distribution Game,' for example, subjects seek to minimize costs as they manage the production and distribution of a commodity (Sterman 1989b, 1992). Though simplified compared to real firms, the task is dynamically complex as it includes multiple feedbacks, time delays, nonlinearities, and accumulations. Average costs were ten times greater than optimal. The subjects generated costly oscillations with consistent amplitude and phase relations, even though demand was essentially constant. Econometric analysis of subjects' decisions showed that people were insensitive to the time delays in the system. People did not account well, and often not at all, for the supply line of orders that had been placed but not yet received, causing them to overcompensate for inventory shortfalls. Facing an inventory shortfall many subjects order enough beer to close the gap. Because of the delay in filling orders, inventory remains depressed, and the next period they order more beer. Still deliveries are insufficient, and they order the needed beer again. Finally, the first order arrives, inventory rises to the desired level, and the subjects cut their orders. But the beer in the supply line continues to arrive, swelling their inventory many times above the desired levels - and causing emotional reactions from anxiety to anger to chagrin. Significantly, subjects often blame their difficulty on exogenous events. When asked to sketch the pattern of customer demand, for example, most draw a large amplitude fluctuation similar to the oscillation they generated. When it is revealed that customer demand was in fact constant, many voice disbelief. 
In a second experiment, (Sterman 1989a), subjects exhibited the same behavior in a simulated macroeconomy representing the capital investment multiplier/accelerator. Analysis of the subjects' decision rules showed they used essentially the same rule as subjects in the beer game study. The estimated parameters again showed most people ignored the time delays and feedback structure of the task, even though each subject was the only decision maker and the structure was completely revealed.

Simulation of the decision rules estimated for the subjects in both experiments showed that approximately one third were intrinsically unstable, so that the system never reached equilibrium. About one-quarter of the estimated rules yield deterministic chaos (Sterman 1988; Sterman 1989c). The heuristics people used interacted with the feedback structure of these systems to yield severe, persistent, and costly oscillations.

These studies led me to suggest that the observed dysfunction in dynamically complex settings arises from 'misperceptions of feedback'. I argued that the mental models people use to guide their decisions are dynamically deficient. Specifically, people generally adopt an event-based, 'open-loop' view of causality, ignore feedback processes, fail to appreciate time delays between action and response and in the reporting of information, do not understand stocks and flows, and are insensitive to nonlinearities that may alter the strengths of different feedback loops as a system evolves.

Subsequent experiments show that the greater the dynamic complexity of the environment, the worse people do relative to potential. Diehl and Sterman (1993) examined the performance of MIT undergraduates in a simple one-person inventory management task. Time delays and sideeffect feedbacks were varied from trial to trial as experimental treatments. We compared subject performance against two benchmarks: optimal behavior and the behavior of a 'do-nothing' rule. The results strongly supported the misperceptions of feedback hypothesis. Overall, subject costs were more than four times greater than optimal, despite financial incentives, training, and repeated play. In the easy conditions (no time delays or feedback effects) subjects dramatically outperformed the 'do-nothing' rule, but in the difficult conditions many were bested by the 'donothing' rule - their attempts to control the system were counterproductive. Regression models 
of subject decision rules showed little evidence subjects adapted their decision rules as the complexity of the task changed. Indeed, when the environment was complex subjects seemed to revert to simple rules that ignored the time delays and feedbacks, leading to degraded performance. There was no significant difference in the time taken to make decisions across the different complexity levels, even though the number of variables to consider is much greater in the difficult conditions.

Paich and Sterman (1993) showed that learning in situations of dynamic complexity is often poor. We designed a management flight simulator representing a common and realistic corporate strategy setting. 10 The simulation portrays the market for a consumer durable product that the subjects manage through the full product life cycle, from launch through decline. The simulation includes realistic features of such markets, including price elasticity effects, marketing, word of mouth, original and replacement demand, competition, learning curves, and capacity acquisition delays. Subjects make price and capacity expansion decisions each quarter for ten simulated years. The subjects played five such trials, each with different characteristics of the market and product. As treatments we varied the strength of the key feedback loops in the simulated market. Results show patterns characteristic of many real consumer durable markets, including boomand-bust, overcapacity, price war, and shakeout. We contrast subject performance against a simple decision rule embodying a naive strategy. The naive strategy does not engage in any strategic or game theoretic reasoning. Indeed, it is insensitive to the feedback structure of the market and the behavior of the competitor. Yet the naive strategy outperforms nearly $90 \%$ of the subjects. Performance relative to potential is degraded significantly as the feedback complexity of the environment grows, consistent with the misperceptions of feedback hypothesis.

Though subjects improved with experience, they learned little: Subjects accumulated fifty years of simulated experience in an environment with perfect, immediate outcome feedback Yet in the last trial the naive strategy still outperformed $83 \%$ of the subjects. Most important, subjects did not learn how to improve their performance in the dynamically complex conditions. Even in the last trial, the stronger the feedback complexity of the environment, the lower profits were relative to potential. The degradation of performance relative to potential caused by high feedback complexity is not moderated by experience. Estimation of subject decision rules showed 
subjects actually became less responsive to critical variables and more vulnerable to forecasting errors - their learning hurt their ability to perform well in the complex conditions.

Other experiments show the misperceptions of feedback are robust to experience, incentives, opportunities for learning, and the presence of market institutions. Kampmann and Sterman (1994) designed an experiment where subjects managed a firm in an experimental economy under various market institutions and feedback complexity conditions. The high feedback complexity condition included production delays and a multiplier feedback from production to aggregate demand; the simple condition had neither. Three market institutions were tested: fixed prices, posted prices, and market clearing prices. Subjects were mostly MIT and Harvard graduate students in economics and were paid in proportion to their profits in the experiment.

In the constant price, dynamically complex condition subjects created the same unstable fluctuations observed in the experiments discussed above. In the simple market clearing condition with no feedback complexity, subjects generally converged to the predicted equilibrium, replicating prior studies in experimental economics.

However, performance relative to optimal in all three price institutions was significantly worse in the complex condition than the simple condition. Even in perfectly functioning markets modest levels of dynamic complexity cause large and systematic deviations from rational behavior. Complexity reduced subjects' ability to reach and maintain the cooperative equilibrium, slowed learning, and reduced the consistency of decisions. In the complex conditions most subjects created sustained 'business cycles' even though the environment was unchanging. As in the beer game they attributed these cycles to exogenous changes in consumer demand.

Process data and regression models of subject decisions showed people used only a few cues, tended to ignore time delays and feedbacks, and forecasted by averaging past values and extrapolating past trends. Subjects actually spent less time making their decisions in the complex markets than the simple markets. Simulations of the estimated rules replicated the aggregate dynamics of the experimental markets with surprising fidelity. Thus while markets may reduce the magnitude of errors caused by the misperceptions of feedback, they do not eliminate them. Even well-functioning markets do not render the bounds on human rationality irrelevant. 
The robustness of the misperceptions of feedback and the poor performance they lead us to create across many domains are due to two basic and related deficiencies in our mental models of complexity. First, our cognitive maps of the causal structure of systems are vastly simplified compared to the complexity of the systems themselves. Second, we are unable to infer correctly the dynamics of all but the simplest causal maps. Both are direct consequences of bounded rationality (Simon 1979, 1982); that is, the many limitations of attention, memory, recall, information processing, and time that constrain human decision making.

3.5 Flawed Cognitive Maps of Causal Relations: Causal attributions are a central feature of mental models. People create, update, and maintain cognitive maps of causal connections among entities and actors, from the prosaic - 'if I touch a flame I will be burned' - to the grand - 'the larger the government deficit, the higher interest rates will be'. Studies of cognitive maps show that few incorporate any feedback loops. Axelrod (1976) found virtually no feedback processes in studies of the cognitive maps of political elites; rather, people tended to formulate intuitive decision trees relating possible actions to probable consequences - an event-level representation. Hall (1976) reports similar open-loop mental maps in a study of the publishing industry. Dörner (1980) found that people tend to think in single strand causal series and had difficulty in systems with side effects and multiple causal pathways (much less feedback loops). Similarly, experiments in causal attribution show people tend to assume each effect has a single cause and often cease their search for explanations when a sufficient cause is found; usually base rates and situational factors are ignored (see the discussion in Plous 1993).

The heuristics we use to judge causal relations lead systematically to cognitive maps that ignore feedbacks, multiple interconnections, nonlinearities, time delays, and the other elements of dynamic complexity. The "causal field" or mental model of the stage on which the action occurs is crucial in framing people's judgments of causation (Einhorn and Hogarth 1986). Within a causal field, people use various "cues to causality" including temporal and spatial proximity of cause and effect, temporal precedence of causes, covariation, and similarity of cause and effect. These heuristics lead to difficulty in complex systems where cause and effect are often distant in time and space, where actions have multiple effects, and where the delayed and distant consequences are often different from and less salient than proximate effects - or simply unknown. 
The multiple feedbacks in complex systems cause many variables to be correlated with one another, confounding the task of judging cause. However, people are poor judges of correlation. In the widely studied 'multiple cue probability learning' paradigm, subjects seek to discover the relationship between a criterion and various cues upon which it depends (along with a random error) by predicting the criterion from the cues and then receiving outcome feedback on the accuracy of their judgment. People can generally detect linear, positive correlations given enough trials - if the outcome feedback is accurate enough. However, people have great difficulty in the presence of random error, nonlinearity, and negative correlations, often never discovering the true relationship (Brehmer 1980).

A fundamental principle of system dynamics states that the structure of the system gives rise to its behavior. However, people have a strong tendency to attribute the behavior of others to dispositional rather than situational factors - the so-called 'fundamental attribution error' (see Ross 1977). In complex systems the same policy (decision rule) can lead to very different behavior (decisions) as the state of the system changes. When we attribute differences in behavior to differences in personality we lose sight of the role of system structure in shaping our choices. The attribution of behavior to individuals and special circumstances rather than system structure systematically diverts our attention from the high leverage points where redesign of the system or governing policy can have significant, sustained, beneficial effects on performance (Forrester 1969, chapter 6; Meadows 1982). When we attribute behavior to people rather than system structure the focus of management becomes the search for extraordinary people to do the job rather than designing the job so that ordinary people can do it.

3.6 Erroneous Inferences about dynamics: Even if our cognitive maps of causal structure were perfect, learning, especially double loop learning, would still be difficult. In order to use a mental model to design a new strategy or organization we must make inferences about the consequences of decision rules that have never been tried and for which we have no data. To do so requires intuitive solution of high-order nonlinear differential equations, a task far exceeding human cognitive capabilities in all but the simplest systems (Forrester 1971, Simon 1982). In several of the experiments discussed above, including the inventory management task in Diehl and Sterman (1993) and the multiplier-accelerator task in Sterman (1989a), subjects were given 
complete knowledge of all structural relationships and parameters, along with perfect, comprehensive, and immediate outcome feedback. The subjects were the only players. Further, the systems were simple enough that the number of cues to consider was small - the multiplieraccelerator task involved only three state variables. Poor performance in these tasks seems to be due to the inability of the subjects to use their perfect knowledge to make reasonable inferences about the dynamics of the system or its response to possible decisions they might make.

People cannot simulate mentally even the simplest possible feedback system, the first-order linear positive feedback loop. The differential equation, $\mathrm{dx} / \mathrm{dt}=\mathrm{gx}$, yields pure exponential growth, $x=x_{0} \exp (g t)$. Such positive feedback processes are commonplace, from the compounding of interest to the growth of populations. Wagenaar and Sagaria (1975) and Wagenaar and Timmers $(1978,1979)$ showed that people significantly underestimate exponential growth, tending to extrapolate linearly rather than exponentially. Using more data points or graphing the data did not help, and mathematical training did not improve performance.

Thus bounded rationality simultaneously constrains the complexity of our cognitive maps and our ability to use them to anticipate the system dynamics. Schemata where the world is seen as a sequence of events and where feedback, nonlinearity, time delays, and multiple consequences are lacking lead to poor performance in settings where these elements of dynamic complexity are prevalent. Dysfunction in complex systems can arise from the misperception of the feedback structure of the environment. But schemata that do account for complexity cannot be used reliably to understand the dynamics. Dysfunction in complex systems can arise from faulty mental simulation - the misperception of feedback dynamics. These two different bounds on rationality must both be overcome for effective learning to occur. Perfect maps without a simulation capability yield little insight; a calculus for reliable inferences about dynamics yields systematically erroneous results when applied to simplistic maps.

3.7 Unscientific Reasoning; Judgmental errors and biases: To learn effectively in a world of dynamic complexity and imperfect information people must develop what Davis and Hogarth (1992) call "insight skills" - the skills that help people learn when feedback is ambiguous:

[T] he interpretation of feedback in the form of outcomes needs to be an active and disciplined task governed by the rigorous rules of scientific inference. Beliefs must be 
actively challenged by seeking possible disconfirming evidence and asking whether alternative beliefs could not account for the facts" (emphasis in original).

Unfortunately, people are poor intuitive scientists, generally failing to reason in accordance with the principles of scientific method. For example, people do not generate sufficient alternative explanations or consider enough rival hypotheses. People generally do not adequately control for confounding variables when they explore a novel environment. People's judgments are strongly affected by the frame in which the information is presented, even when the objective information is unchanged. People suffer from overconfidence in their judgments (underestimating uncertainty), wishful thinking (assessing desired outcomes as more likely than undesired outcomes), and the illusion of control (believing one can predict or influence the outcome of random events). People violate basic rules of probability, believe in the 'law of small numbers', do not understand basic statistical concepts such as regression to the mean, and do not update beliefs according to Bayes' rule. Memory is distorted by hindsight, the availability and salience of examples, and the desirability of outcomes. And so on. Hogarth (1987) discusses 30 different biases and errors documented in decision making research and provides a good guide to the literature (see also Kahneman, Slovic and Tversky 1982). The research convincingly shows that scientists and professionals, not only 'ordinary' people, suffer from many of these judgmental biases.

Among the failures of scientific reasoning most inimical to learning is the tendency to seek evidence consistent with current beliefs rather than potential disconfirmation (Einhorn and Hogarth 1978, Klayman and Ha 1987). In a famous series of experiments, Wason and colleagues presented people tasks of the sort shown in figure $7 .^{11}$ In one version you are shown one side of four cards, each with a letter on one side and a number on the other, say E, K, 4, and 7. You are told that 'if a card has a vowel on it, then it has an even number on the other side.' You must then identify the smallest set of cards to turn over to see if the proposed rule is correct. Wason and Johnson-Laird (1972) found that the vast majority of subjects selected ' $E$ ' or ' $E$ ' and '4' as the answers. Less than four percent gave the correct answer, ' $E$ ' and ' 7 '. The rule has the logical form 'if $p$ then $q$ '. Falsification requires observation of ' $p$ and not- $q$ '. The only card showing ' $p$ ' is the ' $E$ ' card, so it must be examined - the back of the ' $E$ ' card must be an even number if the rule holds. The only card showing 'not-q' is the ' 7 ', so it must be examined. The ' $\mathrm{K}$ ' and ' 4 ' cards are irrelevant. Yet people consistently choose the card showing ' $q$ ', a choice that can only 
provide data consistent with the theory, but cannot test it - if the back of the ' 4 ' is a consonant, you have learned nothing, since the rule is silent about the numbers associated with consonants. Experiments show the tendency to seek confirmation is robust in the face of training in logic, mathematics, and statistics. Search strategies that focus only on confirmation of current beliefs slow the generation and recognition of anomalies that might lead to learning, particularly double loop learning (see also Davis and Hogarth 1992 for examples and discussion).

Some argue that while people err in applying the principles of logic, at least people are rational in the sense that they appreciate the desirability of scientific explanation. Unfortunately, the situation is far worse. The rational, scientific world view is a relatively recent development in human history and remains rare. Many people place their faith in what Dostoyevsky's Grand Inquisitor called "miracle, mystery, and authority," for example, astrology, ESP, UFOs, creationism, conspiracy theories of history, channeling of past lives, cult leaders promising Armageddon, and Elvis sightings. The persistence of such superstitious beliefs depends partly on the bias towards confirming evidence. Wade Boggs, the former Red Sox batting champion, ate chicken every day for years because he once had a particularly good day at the plate after a dinner of lemon chicken (Shaughnessy 1987). During this time Boggs won five batting championships, 'proving' the wisdom of the 'chicken theory'. Consider the continued popularity of astrology, psychics, and economic forecasters, who publicize their 'successes' and suppress their (more numerous) failures. Remember that less than a decade ago the president of the United States and first lady managed affairs of state on the basis of astrology (Robinson 1988). And it worked: he was reelected in a landslide.

Such lunacy aside, there are deeper and more disturbing reasons for the prevalence of these learning failures and the superstitions they engender. Human beings are more than cognitive information processors. We have a deep need for emotional and spiritual sustenance. But from Copernican heliocentrism through evolution, relativity, quantum mechanics and Gödelian uncertainty, science stripped away ancient and comforting structures placing humanity at the center of a rational universe designed for us by a supreme authority. For many people scientific thought leads not to enlightenment but to existential angst and the absurdity of human insignificance in an incomprehensibly vast universe. Others believe science and technology 
were the shock troops for the triumph of materialism and instrumentalism over the sacred and spiritual. These anti-scientific reactions are powerful forces. In many ways they are important truths. They have led to many of the most profound works of art and literature. But they can also lead to mindless new-age psychobabble.

The reader should not be lulled into concluding I am a naive defender of science as it is practiced, nor an apologist for the real and continuing damage done to the environment and to our cultural, moral, and spiritual lives in the name of rationality and progress. On the contrary, I have stressed the research showing that scientists are often as prone to the judgmental errors and biases discussed above as lay people. It is precisely because scientists are subject to the same cognitive limitations and moral failures as others that we experience abominations such as the US government funded research in which plutonium was injected into seriously ill patients, and in which radioactive calcium was fed to retarded children, all without their knowledge or consent (Mann 1994). A central principle of the systems view of the world is to examine issues from multiple perspectives; to expand the boundaries of our mental models to consider the long-term consequences and 'side effects' of our actions, including their environmental, cultural, and moral implications (Meadows, Richardson, and Bruckmann 1982).

\subsection{Defensive Routines and Interpersonal Impediments to Learning: Learning by groups}

can be thwarted even if the system provides excellent information feedback and the decision makers reason well as individuals. We rely on our mental models to interpret the language and acts of others, construct meaning, and infer motives. However, as Forrester (1971) argues,

The mental model is fuzzy. It is incomplete. It is imprecisely stated. Furthermore, within one individual, a mental model changes with time and even during the flow of a single conversation. The human mind assembles a few relationships to fit the context of a discussion. As the subject shifts so does the model.... [E] ach participant in a conversation employs a different mental model to interpret the subject. Fundamental assumptions differ but are never brought into the open.

Argyris (1985), Argyris and Schön (1978), Janis (1982), Schein (1969, 1985, 1987) and others document the defensive routines and cultural assumptions people rely on, often unknowingly, to interact with and interpret their experience of others. We use defensive routines to save face, assert dominance over others, make untested inferences seem like facts and advocate our positions while appearing to be neutral. We make conflicting, unstated attributions about the 
data we receive, fail to distinguish between the sense-data of experience and the attributions and generalizations we readily form from them. We avoid publicly testing our hypotheses and beliefs, and avoid threatening issues. Above all, defensive behavior involves covering up the defensiveness and making these issues undiscussable, even when all parties are aware they exist.

Defensive routines are subtle. They often arrive cloaked in apparent concern and respect for others. Consider the strategy of 'Easing in':

If you are about to criticize someone who might become defensive and you want him to see the point without undue resistance, do not state the criticism openly; instead, ask questions such that if he answers them correctly, he will figure out what you are not saying (Argyris, Putnam, and Smith 1985, 83).

But easing-in often

...creates the very defensiveness that it is intended to avoid, because the recipient typically understands that the actor is easing-in. Indeed, easing-in can be successful only if the recipient understands that he is supposed to answer the questions in a particular way, and this entails the understanding that the actor is negatively evaluating the recipient and acting as if this were not the case (Argyris, Putnam, and Smith 1985, 85).

Defensive behavior, in which the 'espoused theories' we offer to others differ from our 'theories in use', prevent learning by hiding important information from others, avoiding public testing of important hypotheses, and tacitly communicating that we are not open to having our mental models challenged. Defensive routines often yield 'groupthink' (Janis 1982), where members of a group mutually reinforce their current beliefs, suppress dissent, and seal themselves off from those with different views or possible disconfirming evidence. Defensive routines ensure that the mental models of team members remain hidden, ill formed and ambiguous. Thus learning by groups can suffer even beyond the impediments to individual learning.

3.9 Implementation failure: In the real world decisions are often implemented imperfectly, further hindering learning. Even if a team agreed on the proper course of action, the implementation of these decisions can be delayed and distorted as the actual organization responds. Local incentives, asymmetric information, and private agendas can lead to game playing by agents throughout a system. Obviously implementation failures can hurt the organization. Imperfect implementation can defeat the learning process as well, because the management team evaluating the outcomes of their decisions may not know the ways in which the decisions they thought they were implementing were distorted. 
Finally, in the real world of irreversible actions and high stakes the need to maintain performance often overrides the need to learn by suppressing new strategies for fear they would cause present harm even though they might yield great insight and prevent future harm.

\section{Requirements for successful learning in complex systems}

Thus we face grave impediments to learning in complex systems like a nation, firm or family. Every link in the feedback loops by which we might learn can be weakened or cut by a variety of structures. Some of these are physical or institutional features of the environment - the elements of dynamic complexity that reduce opportunities for controlled experimentation, prevent us from learning the consequences of our actions, and distort the outcome feedback we do receive. Some are consequences of our culture, group process and inquiry skills. Still others are fundamental bounds on human cognition, particularly the poor quality of our mental maps and our inability to make correct inferences about the dynamics of complex nonlinear systems.

\subsection{When can evolution overcome the impediments to learning? Given the many impedi-} ments to learning discussed above, how is it possible that people walked on the moon, or even get through the day without grave injury? Reflecting on this paradox, Toda (1962, p. 165) wrote

Man and rat are both incredibly stupid in an experimental room. On the other hand, psychology has paid little attention to the things they do in their normal habitats; man drives a car, plays complicated games, and organizes society, and rat is troublesomely cunning in the kitchen.

Many scholars resolve the paradox by arguing that evolution can lead to high performance without the improvement of our causal maps or accurate mental simulation. Consider learning to ride a bicycle. Few people can write, let alone solve, the equations of motion for the bicycle, yet many master bicycling by the age of six. Such examples - others include billiards (Friedman 1953) - are often cited by economists who believe that human systems rapidly approach optimality through evolution (Lucas 1987). In this view, learning does not require good mental models of the environment. All we require is the ability to generate new candidate decision rules sufficiently different from current procedures and the ability to recognize and reward those that improve performance. Selection of the best performing rules over time will lead to high performance without the need to understand how or why something works.

Evolution does occur, both in the biological world and the social world. Recent work with 
genetic algorithms and other simulated evolutionary processes (Nelson and Winter 1982, Anderson, Arrow and Pines 1988) show that these 'blind' processes often lead to rapid improvements in system performance. However, evolution leads to improvement only to the extent that (1) the processes for generating new candidate rules provide for sufficient variety; (2) the better performing rules are rewarded by more frequent use; and (3) evolution proceeds rapidly compared to changes in the system itself. ${ }^{12}$ Dynamic complexity and the misperceptions of feedback discussed above, however, reduce the effectiveness of all three.

Contrast learning to ride a bicycle with learning to invest successfully in real estate. The real estate industry suffers from chronic cycles of boom and bust. Low vacancy rates lead to high rents and rising prices, causing many new projects to be initiated. Development continues until prices fall as the stock of buildings increases enough to bring the vacancy rate up. However, projects under construction continue to add to the stock of buildings for several years after new development ceases. The stock of buildings overshoots, prices fall, and new construction remains low until vacancies drop, initiating the next cycle (Bakken 1993, Hernandez 1990 and Thornton 1992 describe field studies of successful and unsuccessful developers that verify the account here). The equations of motion for the real estate cycle are much simpler than those governing the bicycle. A simple, low-dimensional system dynamics model replicates the real estate cycle well (Jarmain 1963, Bakken 1993). Yet the boom and bust cycles in real estate persist over centuries (Hoyt 1933), while novice riders quickly learn to pilot their bicycles smoothly. The differences must be sought in the effects of dynamic complexity on the efficacy of the feedbacks governing learning and evolution.

Consider first the bicycle. The conditions for learning are excellent: outcome feedback is available continuously with but short time delays between action and result. Feedback is salient and accurate. There are few confounding variables (what others in the neighborhood are doing is irrelevant). One can cycle around the driveway - and the learning loop - dozens of times in an afternoon. Thus one can try many different ways to ride (variety is easily generated) and can easily determine which work best (thus effectively selecting those that improve performance). In the next round of trials, one generates new experience in the neighborhood of what worked best before, and selects from these the best performing ways to ride. Furthermore the laws of physics 
and equations of motion for the bicycle do not change in response to the rider's decisions, so what is learned does not become obsolete. Thus evolution can work well. ${ }^{13}$

Consider now the problem of successful investing in the real estate industry. Time lags are substantial - it takes two to five years between the decision to develop a property and the completion of the project, still more time to cash out, and the buildings last at least fifty years. Even experienced developers experience only one or at most two cycles in their career, and so much will change over those decades it is difficult to draw general conclusions about the symptoms, much less the causes, of the dynamics. Information about rents, prices, construction costs, vacancies, migration patterns and many other relevant variables is extremely limited, incomplete, noisy, and ambiguous. Current prices and stories of successful deals are highly salient and concrete but misleading, while the critically important supply pipeline and plans of others developers are abstract and unpersuasive. It is extremely difficult to relate current prices and costs to likely future costs and returns. It is not possible to conduct controlled experiments. As developers begin new projects, their actions alter a host of variables including the availability and cost of construction crews, migration patterns and business location decisions, all of which feed back to alter vacancies and prices and thus future development decisions. Unlike the bicycle, in real estate what others in the neighborhood are doing matters a great deal: success in the market rapidly attracts new entrants who then contribute to overbuilding and lead to lower prices.

Evolution functions poorly in the real estate market both because there is much less variation in behavior and because selection is less effective. The slow dynamics mean there are fewer decisions than for the bicycle. Variation and experimentation are reduced due to the strong herd instinct in the industry. Groupthink and strong networks of communication among developers, bankers, and others lead to common knowledge and expectations. The costs of error are also asymmetric: it is better to be wrong with the crowd than wrong alone. Even if a developer wished to follow a contrarian strategy by buying properties when prices are depressed and pessimism reigns, few investors would be willing to lend the needed funds. Experimentation is also reduced because errors are punished much more severely (by bankruptcy and loss of reputation) than the skinned knees typical in bicycling. Without variation in developer strategy, meaningful performance differentials cannot arise, and selection will operate on noise. Finally, 
the feedbacks among market participants are so strong that evolution itself introduces variation in the environment that makes current knowledge obsolete (that is, the players, their strategies, and their environment are co-evolving).

More important, evolution selects according to whatever fitness function is used to evaluate different strategies. Different fitness functions - values - reward different behaviors. When short-run performance is rewarded, strategies yielding superior quarterly or annual results proliferate even though they may cause long-run ruin for all. The bias towards reward of shortrun results is reinforced by the misperceptions of feedback, which make it hard to assign credit for long-term results to particular strategies or people. Most developers and bankers find the structure and dynamics of the industry so hard to understand that the effectiveness of strategies is evaluated well before the full consequences are observed. The short time horizon for performance evaluation is reinforced by perverse incentives whereby deals that ultimately lose money generate fees up front. These incentives are themselves devices to reduce uncertainty about short-term cash flow. Thus during booms strategies based on maximum financial leverage and building 'on spec' work best while conservative investors lag far behind. Aggressive strategies proliferate as the apparent success of players like Donald Trump makes still more capital available to them and draws in a host of imitators. Selection thus rewards strategies that worsen the bust. Rather than leading to stability, evolution may select against conservative investors and increase the prevalence of speculators who destabilize the industry.

4.2 Improving the learning process: What then are the requirements for successful learning in complex systems? If we are to create useful protocols and tools for learning effectively in a world of dynamic complexity we must attend to all of the impediments to learning. Figure 8 shows how the learning feedbacks would operate when all the impediments to learning are addressed. The diagram features a new feedback loop created by the use of 'virtual worlds'. Virtual worlds (the term is Schön's [1983b]) are formal models, or microworlds (Papert 1980), in which the decision makers can refresh decision making skills, conduct experiments, and play. They can be physical models, role plays, or computer simulations. In systems with significant dynamic complexity, computer simulation will typically be needed (though there are notable exceptions, such as the beer distribution game and the Du Pont Maintenance Game (Carroll, 
Marcus and Sterman 1994), along with role-play/computer hybrids such as Fish Banks, Ltd. (Meadows, Fiddaman and Shannon 1993).

Virtual worlds have several virtues. First, they provide low-cost laboratories for learning. The virtual world allows time and space to be compressed or dilated. Actions can be repeated under the same or different conditions. One can stop the action to reflect. Decisions that are dangerous, infeasible, or unethical in the real system can be taken in the virtual world. Thus controlled experimentation becomes possible, and the time delays in the learning loop through the real world are dramatically reduced. In the real world the irreversibility of many actions and the need to maintain high performance often override the goal of learning by preventing experiments with untried possibilities ('if it ain't broke, don't fix it'). In the virtual world one can try strategies that one suspects will lead to poor performance or even (simulated) catastrophe. Often pushing a system into extreme conditions reveals more about its structure and dynamics than incremental adjustments to successful strategies. Virtual worlds are the only practical way to experience catastrophe in advance of the real thing. Thus a great deal of the time pilots spend in flight simulators is devoted to extreme conditions such as engine failure or explosive decompression.

Virtual worlds provide high-quality outcome feedback. In the People Express Management Flight Simulator (Sterman 1988), for example, and similar system dynamics simulations, players receive perfect, immediate, undistorted, and complete outcome feedback. In an afternoon one can gain years of simulated 'experience'. The degree of random variation in the virtual world can be controlled. Virtual worlds offer the learner greater control over strategy, leading to more consistency of decision making, avoiding implementation failure and game playing. In contrast to the real world, which, like a black box, has a poorly resolved structure, virtual worlds can be 'open boxes' whose assumptions are fully known and can even be modified by the learner.

Virtual worlds for learning and training are commonplace in the military, in pilot training, in power plant operations, and in many other real-time tasks where human operators interact with complex technical systems. Virtual worlds are also common in professions such as architecture (Schön 1983b). The use of virtual worlds in managerial tasks, where the simulation compresses into a day or hour dynamics extending over years or decades, is more recent and less widely 
adopted. Yet these are precisely the settings where dynamic complexity is most problematic, and the learning feedbacks described above least effective. Many virtual worlds for the study of dynamically complex settings have now been developed, and while further evaluative research is needed, they have enjoyed great success in precollege education, universities, and corporations (see Gould 1993, Graham, Morecroft, Senge, and Sterman 1992, Morecroft and Sterman 1994 and Mandinach and Cline 1994).

4.3 Pitfalls of Virtual Worlds: Virtual worlds are effective when they engage people in what Dewey called "reflective thought" and what Schön (1992) calls "reflective conversation with the situation." While the use of a virtual world may be necessary for effective learning in dynamically complex systems, they do not guarantee that virtual worlds overcome the flaws in our mental models, scientific reasoning skills, and group process.

Obviously, while the virtual world enables controlled experimentation, it does not require the learner to apply the principles of scientific method. Many participants in model-based workshops lack training in scientific method and awareness of the pitfalls in the design and interpretation of experiments. A commonly observed behavior in workshops using management flight simulators is 'trial and trial again' where players make incremental adjustments to their last strategy, then try again. Participants do not take time to reflect on the outcome, identify discrepancies between the outcomes and their expectations, formulate hypotheses to explain the discrepancies, and then devise experiments to discriminate among the competing alternatives (Mass [1991] gives guidelines for effective experimentation in simulation models). Effective learning in virtual worlds will often require training for participants in scientific method. Protocols for the use of simulations should be structured to encourage proper procedure, such as keeping laboratory notebooks, explicitly formulating hypotheses and presenting them to the group, and so on.

Defensive routines and groupthink can operate in the learning laboratory just as in the real organization. Indeed, protocols for effective learning in virtual worlds such as public testing of hypotheses, accountability and comparison of different strategies can be highly threatening, inducing defensive reactions that prevent learning (Isaacs and Senge 1992). The use of virtual worlds to stimulate learning in organizations often requires that the group spend time addressing 
their own defensive behavior. Managers unaccustomed to disciplined scientific reasoning and an open, trusting, environment with learning as its goal will have to build these basic skills before a virtual world can prove useful. Developing these skills takes effort and practice.

Still, settings with high dynamic complexity can garble the reflective conversation between the learner and the situation. Long time delays, causes and effects that are distant in time and space, and the confounding effects of multiple nonlinear feedbacks can slow learning even for people with good insight and group process skills. Learning in virtual worlds can be accelerated when the protocols for simulator use help people learn how to represent complex feedback structures and understand their implications. To learn when dynamic complexity is high participants must have confidence in the external validity of the virtual world. They must believe it mimics the relevant parts of the real world well enough that the lessons emerging from the virtual world apply to the real one. To develop such confidence the virtual world must be an open box whose assumptions are accessible and modifiable. To learn from the open box, participants must become modelers, not merely players in a simulation.

In practice, effective learning from models occurs best, and perhaps only, when the decision makers participate actively in the development of the model. Modeling here includes the elicitation of the participants' existing mental models, including articulating the issues (problem structuring), selecting the model boundary and time horizon, and mapping the causal structure of the relevant system. Researchers in the soft-OR tradition have pioneered many methods to facilitate the elicitation and mapping process. Along with techniques developed in system dynamics, many tools and protocols for group model-building are now available, including causal loop diagrams, policy structure diagrams, hexagon modeling, interactive computer mapping, and various problem structuring and soft systems methods (see e.g. Checkland 1981, Eden, Jones \& Sims 1983, Lane 1993, Morecroft 1982, Morecroft and Sterman 1994, Reagan-Cirincione et al. 1991, Richmond 1987, 1993, Rosenhead 1989, Senge and Sterman 1992, and Wolstenholme 1990).

4.4 Why simulation is essential. Eliciting and mapping the participants' mental models, while necessary, is far from sufficient. As discussed above, the temporal and spatial boundaries of our mental models tend to be too narrow. They are dynamically deficient, omitting feedbacks, time 
delays, accumulations, and nonlinearities. The great virtue of many protocols and tools for elicitation is their ability to improve our models by encouraging people to identify the elements of dynamic complexity normally absent from mental models. However, most problem structuring methods yield qualitative models showing causal relationships, but omitting the parameters, functional forms, exogenous variables, and initial conditions needed to fully specify and test the model. Regardless of the form of the model or technique used, the result of the elicitation and mapping process is never more than a set of causal attributions, initial hypotheses about the structure of a system, which must then be tested.

Simulation is the only practical way to test these models. The complexity of the cognitive maps produced in an elicitation workshop vastly exceeds our capacity to understand their implications. Qualitative maps are simply too ambiguous and too difficult to simulate mentally to provide much useful information on the adequacy of the model structure, nor guidance about the future development of the system or the effects of policies.

Without simulation, even the best maps can only be tested and improved by relying on the learning feedback through the real world. As we have seen, this feedback is very slow and often rendered ineffective by dynamic complexity, time delays, inadequate and ambiguous feedback, poor reasoning skills, defensive reactions, and the costs of experimentation. In these circumstances simulation becomes the only reliable way to test the hypotheses emerging from elicitation techniques and other problem structuring methods.

Some scholars argue that it is not possible to create valid formal models of human systems; that formal modeling can at best provide quantitative precision within preexisting problem definitions but cannot lead to fundamentally new conceptions (for various views see Dreyfus and Dreyfus 1986 and the discussion in Lane 1993). On the contrary, formalizing qualitative models and testing them via simulation often leads to radical changes in the way we construe reality and carve problems out of 'messes' (Ackoff 1979). Simulation speeds and strengthens the learning feedbacks. Discrepancies between the formal and mental model stimulate improvements in both, including changes in basic assumptions such as model boundary, time horizon and dynamic hypotheses (see Forrester 1985 and Homer 1992 for philosophy and an example). Without the 
discipline and constraint imposed by the rigorous testing enabled by simulation, it becomes all too easy for mental models to be driven by unconscious bias or deliberate ideology.

Some argue that formalization forces the modeler to omit important aspects of the problem to preserve tractability and enable theorems to be proved, or to omit soft variables for which no numerical data exist. These are indeed dangers. The literature of the social sciences is replete with models in which elegant theorems are derived from questionable axioms, where simplicity dominates utility, and where variables known to be important are ignored because data to estimate parameters are unavailable. System dynamics was designed specifically to overcome these limitations, and from the beginning stressed the development of useful, realistic models, models unconstrained by the demands of analytic tractability, based on realistic assumptions about human behavior, grounded in field study of decision making, and utilizing the full range of available data, not only numerical data, to specify and estimate relationships (see Forrester 1987).

As to the notion that 'useful' and 'valid' formal models of human behavior cannot be developed, space does not permit full rebuttal of this position here. However, as Kenneth Boulding points out, "anything that exists is possible" and many formal models of human behavior in systems with 'soft' variables exist (see, e.g., the models in Levine and Fitzgerald 1992, Roberts 1978, Langley et al. 1987, Sterman 1985, Homer 1985, and many of the models cited in Sastry and Sterman 1993).

Is it possible to learn effectively in complex settings without simulation? Can the use of problem structuring methods, elicitation techniques, and other qualitative systems methods overcome the impediments to learning? If intuition is developed highly enough, if systems thinking is incorporated in precollege education early enough, or if we are taught how to recognize a set of 'system archetypes' (Senge 1990), will we be able to improve our intuition about complex dynamics enough to render simulation unnecessary?

The answer is clearly no. It is true that systems thinking techniques, including system dynamics and qualitative methods such as soft systems analysis, can enhance our intuition about complex situations, just as studying physics can improve our intuition about the natural world. ${ }^{14}$ As Wolstenholme (1990) argues, qualitative systems tools should be made widely available so that 
those with limited mathematical background can benefit from them. I am a strong advocate for the introduction of system dynamics and related methods at all levels of the educational system. Yet even if children began serious study of physics in kindergarten, and continued it through a Ph.D., it is ludicrous to suggest that they could predict the track of a hurricane or understand what happens when two galaxies collide by intuition alone. Many human systems are just as complex. Even if children learn to think in systems terms - a goal I believe is vitally important it will still be necessary to develop formal models, solved by simulation, to learn about such systems.

Most important, when experimentation in the real system is infeasible, simulation becomes the main, and perhaps the only, way learners can discover for themselves how complex systems work. The alternative is rote learning based on the authority of the teacher and textbook, a pedagogy that dulls creativity and stunts the development of the scientific reasoning skills needed to learn about complexity.

\section{Conclusion}

Complex dynamic systems present multiple barriers to learning. The challenge of bettering the way we learn about these systems is itself a classic systems problem. Overcoming the barriers to learning requires a synthesis of many methods and disciplines, from mathematics and computer science to psychology and organizational theory. Theoretical studies must be integrated with field work. Interventions in real organizations must be subjected to rigorous follow up research.

There are many reasons for hope. Recent advances in interactive modeling, tools for representation of feedback structure and simulation software make it possible for anyone to engage in the modeling process. Corporations, universities, and schools are experimenting vigorously. Much further work is needed to test the utility of the tools and protocols, evaluate their impact on individual and organizational learning, and develop effective ways to train others to use them. The more rigorously we apply the principles discussed here to our own theories and our own practices, the faster we will learn how to learn in and about complex systems. 


\section{Notes}

1 By 'scientific' I mean an endeavor much like the 'normal science' of Thomas Kuhn (1970), i.e. the disciplined activity of a community that builds a cumulative stock of knowledge according to certain principles, including documentation and publication of methods and results, replicability, and transferability (the knowledge can be learned and used by others).

2 Depending on the time delays and other elements of dynamic complexity in the system, these examples may not converge. It takes but little ice, fog, fatigue or alcohol to cause an accident, and equilibrium eludes many industries that experience chronic business cycles.

3 See Science, 256, (12 June 1992), 1520-1521.

4 Even more obviously, our ability to see a three dimensional world is the result of extensive modeling by the visual processing system, since the retina images a planar projection of the visual field.

5 Technically, negative loops with no time delays are first-order; the eigenvalue of the linearized system can only be real and oscillation is impossible. Adding delays (state variables) allows the eigenvalues to become complex conjugates, yielding oscillatory solutions. Whether the oscillations of the linearized system are damped or expanding depends on the parameters. All else equal, the more phase lag in a control loop the less stable the system will be.

6 Philosophers have long noted the critical role of beliefs in conditioning perception. A brief summary is provided in Sterman (1985).

7 These data are summarized in Culotta and Koshland 1993.

8 The example is not merely an example of hindsight bias. Given the weak theoretical basis for and null results of the sterilizing immunity approach, it does not seem reasonable to design vaccination trials so that the experiments could generate data only on the one hypothesis of sterilizing immunity. Far from illustrating hindsight bias the example illustrates the overconfidence bias (too much faith that sterilizing immunity would work) and the failure to generate sufficient alternative hypotheses. It is too soon to know which approach will work, if either, and the example does not imply that work on sterilizing immunity should stop. But the favored hypothesis led to experimental protocols that precluded the observation of data that 
might have led to other possibilities, thus slowing learning.

9 Despite its difficulties am not arguing that econometrics should be abandoned. On the contrary, wise use of statistical estimation is important to good system dynamics practice, and more effort should be devoted to the use of these tools in simulation model development and testing.

10 This and other management flight simulators are available from the author.

11 The summary of the Wason test is drawn from Plous 1993, chapter 20.

12 Of course, in systems such as an ecosystem or market evolution is itself a source of change. Such systems involve populations of entities all mutually co-evolving, so that the evolutionary landscape shifts because of the evolutionary process itself.

13 Perhaps most important, bicycling is a motor skill drawing on neural and sensory systems that evolved to provide accurate feedback about and control of balance, position, and motion. Balancing and pedaling require little conscious effort. The decision to invest in real estate, in contrast, is largely conscious and cognitive (though emotions often loom large as well). High survival value over millions of years caused excellent motor skills to evolve, while the cognitive skills required to understand the assumptions behind a spreadsheet or the dynamic complexity of a market have led to reproductive advantage only recently, if at all.

14 Such education is desperately needed. When asked the question

"If a pen is dropped on a moon, will it:
A) Float away
B) Float where it is
C) Fall to the surface of the moon?"

48 out of 168 students in physics courses at Iowa State University gave incorrect answers. A typical student explanation was "The gravity of the moon can be said to be negligible, and also the moon's a vacuum, there is no external force on the pen. Therefore it will float where it is." (Partee, personal communication, 1992). 


\section{References}

Adams, H. 1918. The Education of Henry Adams. Boston: Houghton-Mifflin.

Ackoff, R. 1979. The future of operational research is past. Journal of the Operational Research Society. 30, 93-104.

Anderson, P. Arrow, K, and Pines, D, eds. 1988. The Economy as an Evolving Complex System.. Redwood City, CA: Addison-Wesley.

Argyris, C. 1985. Strategy, Change, and Defensive Routines, Boston: Pitman.

Argyris, C., Putnam, R. and Smith, D. 1985. Action Science. San Francisco: Jossey-Bass.

Argyris, C. and D. Schön 1978. Organizational Learning: a Theory of Action Approach, Reading, Mass: Addison-Wesley.

Axelrod, R. 1976. The Structure of Decision: the cognitive maps of political elites. Princeton: Princeton University Press.

Bakken, B. 1993. Learning and Transfer of Understanding in Dynamic Decision Environments. Unpublished Ph.D. Dissertation, MIT Sloan School of Management, Cambridge MA 02142.

Bower, G. and D. Morrow. 1990. Mental Models in Narrative Comprehension. Science. 247 (5 January) 44-48.

Brehmer, B. 1980. In one word: Not from Experience, Acta Psychologica. 45, 223-241.

Brehmer, B. 1989. Feedback Delays and Control in Complex Dynamic Systems, in Milling, P. and E. Zahn (eds), Computer Based Management of Complex Systems. Berlin: Springer Verlag, 189-196.

Brehmer, B. 1992. Dynamic Decision Making: Human Control of Complex Systems. Acta Psychologica 81, 211-241.

Bruner, J. S. and Postman, L. J. 1949. On the perception of incongruity: A paradigm. Journal of Personality. 18, 206-223.

Carroll, J. S., Sterman, J. D., \& Marcus, A. A. 1994. Playing the Maintenance Game: How Mental Models Drive Organizational Decisions. In Stern, R. R. \& Halpern, J. J., eds., Nonrational Elements of Organizational Decision Making Ithaca, NY: ILR Press.

Checkland, P. 1981. Systems Thinking, Systems Practice. Wiley: Chichester.

Cheng, P. and Nisbett, R. 1985. Pragmatic Reasoning Schemas. Cognitive Psychology. 17, 391-416. 
Cobb, J. and Daly, H. 1989. For the Common Good. Boston: Beacon Press.

Cohen, J. 1993. A new goal: preventing disease, not infection. Science, 262 (17 December), 1820-1821.

Culotta, E. and Koshland, D. 1993. Molecule of the year. Science. 262 (24 December) 1960.

Davis, H. and R. Hogarth 1992. Rethinking Management Education: A View from Chicago. Selected paper 72, University of Chicago, Graduate School of Business.

Diehl, E., \& Sterman, J. D. 1993. Effects of Feedback Complexity on Dynamic Decision Making. Working Paper, Sloan School of Management, Cambridge, MA 02142.

Dörner, D. 1980. On the difficulties people have in dealing with complexity. Simulations and Games. 11(1), 87-106.

Dreyfus, H. L. and S. E. Dreyfus. 1986. Mind over Machine. New York: Free Press.

Eden, C., S. Jones, D. Sims. 1983. Messing About in Problems. Oxford: Pergamon Press.

Einhorn, H. and Hogarth, R. 1978. Confidence in judgment: Persistence of the illusion of validity. Psychological Review. 85, 395-476.

Einhorn, H. and Hogarth, R. 1986. Judging probable cause. Psychological Bulletin. 99, 3-19.

Farman, J. Gardiner, B. and Shanklin, J. 1985. Large losses of total ozone in Antarctica reveal seasonal ClO/NO2 interaction. Nature. 315, 207.

Forrester, J. W. 1961. Industrial Dynamics. Cambridge: MIT Press.

Forrester, J. W. 1971. Counterintuitive Behavior of Social Systems, Technology Review, 73, 3 (January), 52-68.

Forrester, J. W. 1969. Urban Dynamics. Cambridge: MIT Press.

Forrester, J. W. 1985. "The" model versus a modeling "process". System Dynamics Review. 1(1), 133-134.

Forrester, J. W. 1987. 14 'Obvious Truths'. System Dynamics Review. 3(2), 156-159.

Forrester, J. W. 1992. Policies, Decisions, and Information Sources for Modeling. European Journal of Operational Research. 59(1), 42-63.

Friedman, M. 1953. The methodology of positive economics. In Friedman, M, ed., Essays in Positive Economics. Chicago: University of Chicago Press. 
Funke, J. 1991. Solving Complex Problems: Exploration and Control of Complex Systems, in

R. Sternberg and P. Frensch (eds.), Complex Problem Solving: Principles and Mechanisms.

Hillsdale, NJ: Lawrence Erlbaum Associates.

Gentner, D. and Stevens, A. 1983. Mental Models. Hillsdale, NJ,: Lawrence Erlbaum Associates.

Graham, A. K., Morecroft, J. D., Senge, P. M., \& Sterman, J. D. 1992. Model Supported Case Studies for Management Education. European Journal of Operational Research, 59(1), 151166.

Gould, J. 1993. Systems thinking in education. Special issue of the System Dynamics Review. 9(2).

Halford, G. 1993. Children's Understanding: The Development of Mental Models. Hillsdale, NJ,: Lawrence Erlbaum Associates.

Hall, R. I. 1976. A System Pathology of an Organization: The Rise and Fall of the Old Saturday Evening Post. Administrative Science Quarterly, 21(2), 185-211.

Hernandez, K. 1990. Learning in Real Estate: The Role of the Development System in Creating Oversupply. Unpublished S.M. Thesis, MIT Sloan School of Management, Cambridge, MA 02142.

Hogarth, R. 1981. Beyond Discrete Biases: Functional and Dysfunctional Aspects of Judgmental Heuristics, Psychological Bulletin. 90. 197-217.

Hogarth, R. 1987. Judgement and Choice. 2nd Edition. Chichester: John Wiley.

Homer, J. 1992. Cocaine use in America: the evolution of a dynamic model in Anderson, D., Richardson, G. \& Sterman, J., System Dynamics '90: Proceedings of the 1990 International System Dynamics Conference, Boston, 495-510.

Homer, J. B. 1985. Worker Burnout: A Dynamic Model with Implications for Prevention and Control. System Dynamics Review 1 (1): 42-62.

Hoyt, H. 1933. One Hundred Years of Land Values in Chicago. Chicago: University of Chicago Press.

Isaacs, W. and Senge, P. 1992. Overcoming limits to learning in computer-based learning environments. European Journal of Operational Research. 59(1), 183-196. 
Janis, I. L. 1982. Groupthink: Psychological studies of policy decisions and fiascoes (2nd ed.). Boston: Houghton Mifflin.

Jarmain, W. E. 1963. Problems in Industrial Dynamics. Cambridge, MA: MIT press.

Johnson-Laird, P. 1983. Mental Models: Toward a Cognitive Science of Language, Inference, and Consciousness. Cambridge, England: Cambridge University Press.

Kahneman, D., P. Slovic, and A. Tversky. 1982. Judgment Under Uncertainty: Heuristics and Biases, Cambridge: Cambridge University Press.

Kampmann, C. and Sterman, J. 1994. Feedback Complexity, bounded rationality, and market dynamics. Working paper, System Dynamics Group, MIT Sloan School of Management, Cambridge MA 02142.

Klayman, J. and Ha, Y. 1987. Confirmation, disconfirmation, and information in hypothesis testing. Psychological Review. 94: 211-28.

Kleinmuntz, D., and J. Thomas 1987. The value of action and inference in dynamic decision making, Organizational Behavior and Human Decision Processes, 39(3), 341-364.

Kofman, F., Repenning, N, \& Sterman, J. 1994. Unanticipated Side Effects of Successful Quality Programs: Exploring a Paradox of Organizational Improvement. Working Paper D-4390, System Dynamics Group, MIT Sloan School of Management, Cambridge MA 02142.

Kuhn, T. 1970. The Structure of Scientific Revolutions. 2nd ed. Chicago: University of Chicago Press.

Lane, D. 1993. With a little help from our friends: How third generation system dynamics and the problem structuring techniques of 'soft' OR can learn from each other. In Zepeda, E. \& Machuca, J. (Ed.), Proceedings of the 1993 International System Dynamics Conference. Cancún, Mexico: Monterrey Institute of Technology, 235-244.

Langley, P., H. A. Simon, G. L. Bradshaw, and J. M. Zytkow 1987. Scientific Discovery: Computational Explorations of the Creative Processes. Cambridge: The MIT Press.

Leamer, E. 1983. Let's Take the Con out of Econometrics. American Economic Review, 73(1), 31-43.

Levine, R. and H. Fitzgerald. 1992. Analysis of Dynamic Psychological Systems. 2 Vols. New York: Plenum Press. 
Lucas, R. 1987. Adaptive behavior and economic theory. In Hogarth, R. and Reder, M., eds., Rational Choice: The contrast between economics and psychology. Chicago: University of Chicago Press.

Machiavelli, N. 1979. Discourses. In Bondanella, P and Musa, M. (eds. and trans.) The Portable Machiavelli. New York: Viking Press.

Mandinach, E. and H. Cline. 1994. Classroom Dynamics: Implementing a technology-based learning environment. Hillsdale, NJ: Lawrence Erlbaum Associates.

Mann, C. 1994. Radiation: Balancing the Record. Science. 263 (28 January), 470-473.

Mass, N. 1991. Diagnosing surprise model behavior: a tool for evolving behavioral and policy insights. System Dynamics Review. 7(1), 68-86.

Meadows, D. H. 1982. Whole Earth Models and Systems. CoEvolution Quarterly. Summer. 98108.

Meadows, D. H., Meadows, D. L., Randers, J. 1992. Beyond the Limits. Post Mills, VT: Chelsea Green Publishing Company.

Meadows, D. H., J. Richardson, and G. Bruckmann. 1982. Groping in the Dark. London: john Wiley and Sons.

Meadows, D. L., Fiddaman, T., and Shannon, D. 1993. Fish Banks, Ltd. A Micro-computer Assisted Group Simulation that Teaches Principles of Sustainable Management of Renewable Natural Resources. 3rd edition. Laboratory for Interactive Learning, Hood House, University of New Hampshire, Durham, NH 03824.

Molina, M. and Rowland, F. S. 1974. Stratospheric sink for chlorofluoromethanes: Chlorine atomic catalysed destruction of ozone. Nature, 249, 810.

Morecroft, J. 1982. A Critical Review of Diagramming Tools for Conceptualizing Feedback models, Dynamica, 8(I), 20-29.

Morecroft, J. D. W., \& Sterman, J. D., eds. 1994. Modeling for Learning. Portland, OR: Productivity Press.

Nelson, R. and Winter, S. 1982. An Evolutionary Theory of Economic Change. Cambridge, MA: Harvard University Press.

Paich, M. and Sterman, J. 1993. Boom, Bust, and Failures to Learn in Experimental Markets. Management Science, 39(12), 1439-1458. 
Partee, J. 1993. Heavy Boots. E-mail from partee@iastate.edu.

Papert, S. 1980. Mindstorms. New York: Basic Books.

Plous, S. 1993. The psychology of judgment and decision making. New York: McGraw Hill.

Powers, W. 1973. Feedback: Beyond Behaviorism. Science. 179, 351-356.

Reagan-Cirincione, P., Schuman, S., Richardson, G., \& Dorf, S. 1991. Decision modeling: Tools for strategic thinking. Interfaces. 21(6), 52-65.

Richardson, G. 1991. Feedback Thought in Social Science and Systems Theory. Philadelphia: University of Pennsylvania Press.

Richmond, B. 1993. Systems Thinking: critical thinking skills for the 1990s and beyond. System Dynamics Review. 9(2), 113-134.

Richmond, B. 1987. The Strategic Forum: From Vision to Operating Policies and Back Again, High Performance Systems, 13 Dartmouth College Highway, Lyme, NH 03768.

Roberts, E. B., ed. 1978. Managerial Applications of System Dynamics. Portland, OR: Productivity Press.

Robinson, J. 1988. A Day for the Capital to Consider its Stars. Boston Globe. (Wed. 4 May) 1. Rosenhead, J., ed. 1989. Rational Analysis for a Problematic World: Problem Structuring Methods for Complexity, Uncertainty, and Conflict. Chichester: John Wiley and Sons.

Ross, L. 1977. The intuitive psychologist and his shortcomings: Distortions in the attribution process. In L. Berkowitz (ed.), Advances in experimental social psychology, vol. 10. New York: Academic Press.

Sastry, A., \& Sterman, J. D. 1993. Desert Island Dynamics: An Annotated Guide to the Essential System Dynamics Literature. In Zepeda, E. \& Machuca, J. (Ed.), Proceedings of the 1993 International System Dynamics Conference. Cancún, Mexico: Monterrey Institute of Technology, 466-475.

Schank, R. and R. Abelson. 1977. Scripts, Plans, Goals, and Understanding. Hillsdale, NJ: Lawrence Erlbaum Associates.

Schein, E. 1969. Process Consultation: Its Role in Organization Development. Reading, MA: Addison-Wesley.

Schein, E. 1987. Process Consultation, Volume II, Reading, MA: Addison-Wesley. 
Schein, E. 1985. Organizational Culture and Leadership. San Francisco: Jossey-Bass.

Schneiderman, A. 1988. Setting Quality Goals, Quality Progress. April, 55-57.

Schön, D. 1983a. Organizational Learning, in Morgan, G., ed. Beyond Method. London: Sage.

Schön, D. 1983b. The Reflective Practitioner, New York: Basic Books.

Schön, D. 1992. The Theory of Inquiry: Dewey's Legacy to Education. Curriculum Inquiry. 22(2), 119-139.

Senge, P. 1990. The Fifth Discipline: The Art and Practice of the Learning Organization. New York: Doubleday.

Senge, P., \& Sterman, J. D. 1992. Systems Thinking and Organizational Learning: Acting

Locally and Thinking Globally in the Organization of the Future. European Journal of Operational Research, 59(1), 137-150.

Shaughnessy, D. 1987. Bogged Down. Boston Globe. (Sunday 15 March) section 3, 20.

Shewhart, W. 1939. Statistical Method from the viewpoint of quality control. Washington, DC: US Department of Agriculture.

Shiba, S., Graham, A., and Walden, D. 1993. A New American TQM: Four Practical

Revolutions in Management. Portland, OR: Productivity Press.

Simon, H. A. 1979. Rational Decision-making in Business Organizations. American Economic Review, 69, 493-513.

Simon, H. A. 1982. Models of Bounded Rationality. Cambridge: The MIT Press.

Smith, V., Suchanek, G., and A. Williams. 1988. Bubbles, Crashes, and Endogenous

Expectations in Experimental Spot Asset Markets, Econometrica, 56(5), 1119-1152.

Sterman, J. D. 1992. Teaching Takes Off: Flight Simulators for Management Education. OR/MS Today(October), 40-44.

Sterman, J. 1989a. Misperceptions of Feedback in Dynamic Decision Making. Organizational Behavior and Human Decision Processes. 43(3), 301-335.

Sterman, J. 1989b. Modeling Managerial Behavior: Misperceptions of Feedback in a Dynamic Decision Making Experiment. Management Science. 35(3), 321-339.

Sterman, J. D. 1989c. Deterministic Chaos in an Experimental Economic System. Journal of Economic Behavior and Organization, 12, 1-28. 
Sterman, J. D. 1988. People Express Management Flight Simulator. Software and Briefing Book. Available from author, Sloan School of Management, MIT, Cambridge MA 02139.

Sterman, J. D. 1985. The Growth of Knowledge: Testing a Theory of Scientific Revolutions with a Formal Model. Technological Forecasting and Social Change, 28(2), 93-122.

Stolarski, R. and Cicerone, R. 1974. Stratospheric chlorine: A possible sink for ozone. Canadian Journal of Chemistry. 52, 1610.

Toda, M. 1962. The design of a fungus-eater: A model of human behavior in an unsophisticated environment. Behavioral Science. 7, 164-83.

Thornton, L. 1992. Real Estate Development Firms as Learning Organizations: Systems Thinking as a Methodology for Strategic Planning. Unpublished SM Thesis, MIT Center for Real Estate Development, Cambridge MA 02142.

Vennix, J. 1990. Mental Models and Computer Models. Ph.D. thesis. Nijmegen, The, Netherlands: Nijmegen Institute for Cognition Research and Information Technology. Wagenaar, W. and S. Sagaria. 1975. Misperception of exponential growth. Perception and Psychophysics 18: 416-422.

Wagenaar, W. and H. Timmers. 1978. Extrapolation of exponential time series is not enhanced by having more data points. Perception and Psychophysics 24: 182-184.

Wagenaar, W. and H. Timmers. 1979. The pond-and duckweed problem: Three experiments in the misperception of experimental growth. Acta Psychlogica 43: 239-251.

Walton, M. 1986. The Deming Management Method. New York: Dodd, Mead \& Co.

Wason, P. and Johnson-Laird, P. 1972. Psychology of reasoning: Structure and content.

Cambridge, MA: Harvard University Press.

Wolstenholme, E. F. 1990. System Enquiry - A System Dynamics Approach. Chichester: John Wiley. 
Figure 1. Learning is a feedback process. The feedback from the real world to the decision maker includes all forms of information, both quantitative and qualitative.

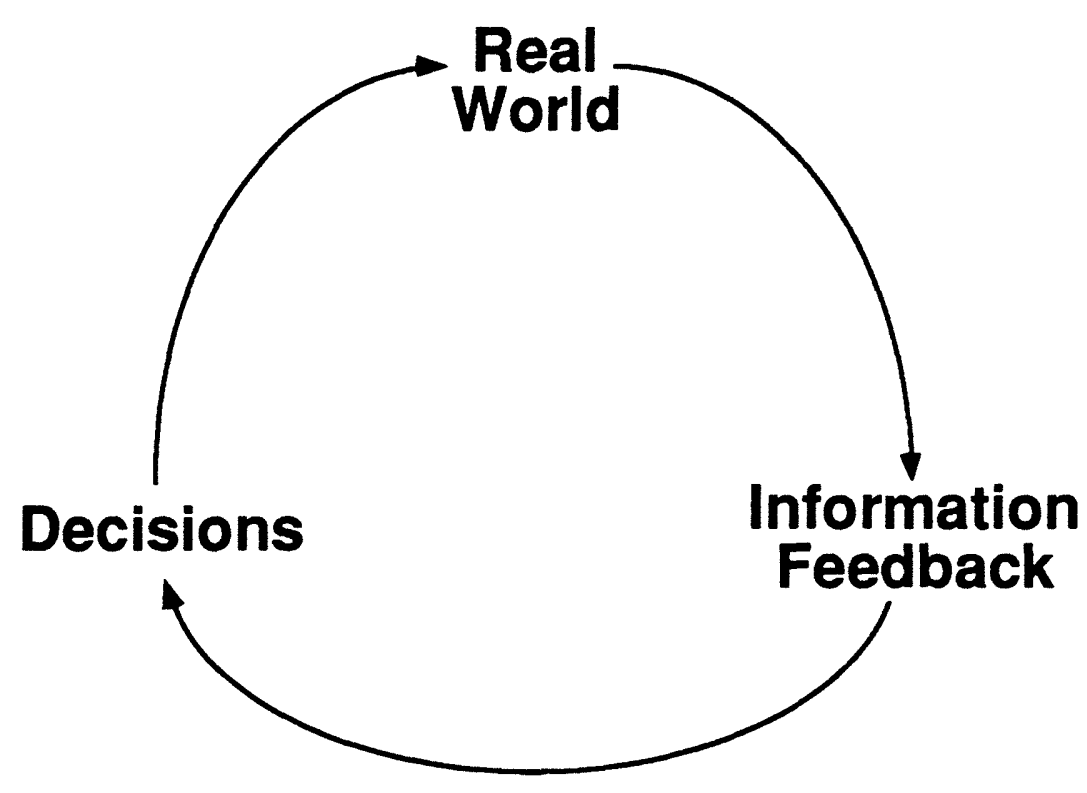


Figure 2. The learning feedback operates in the context of existing decision rules, strategies, culture, and institutions; which in turn are derived from our prevailing mental models.

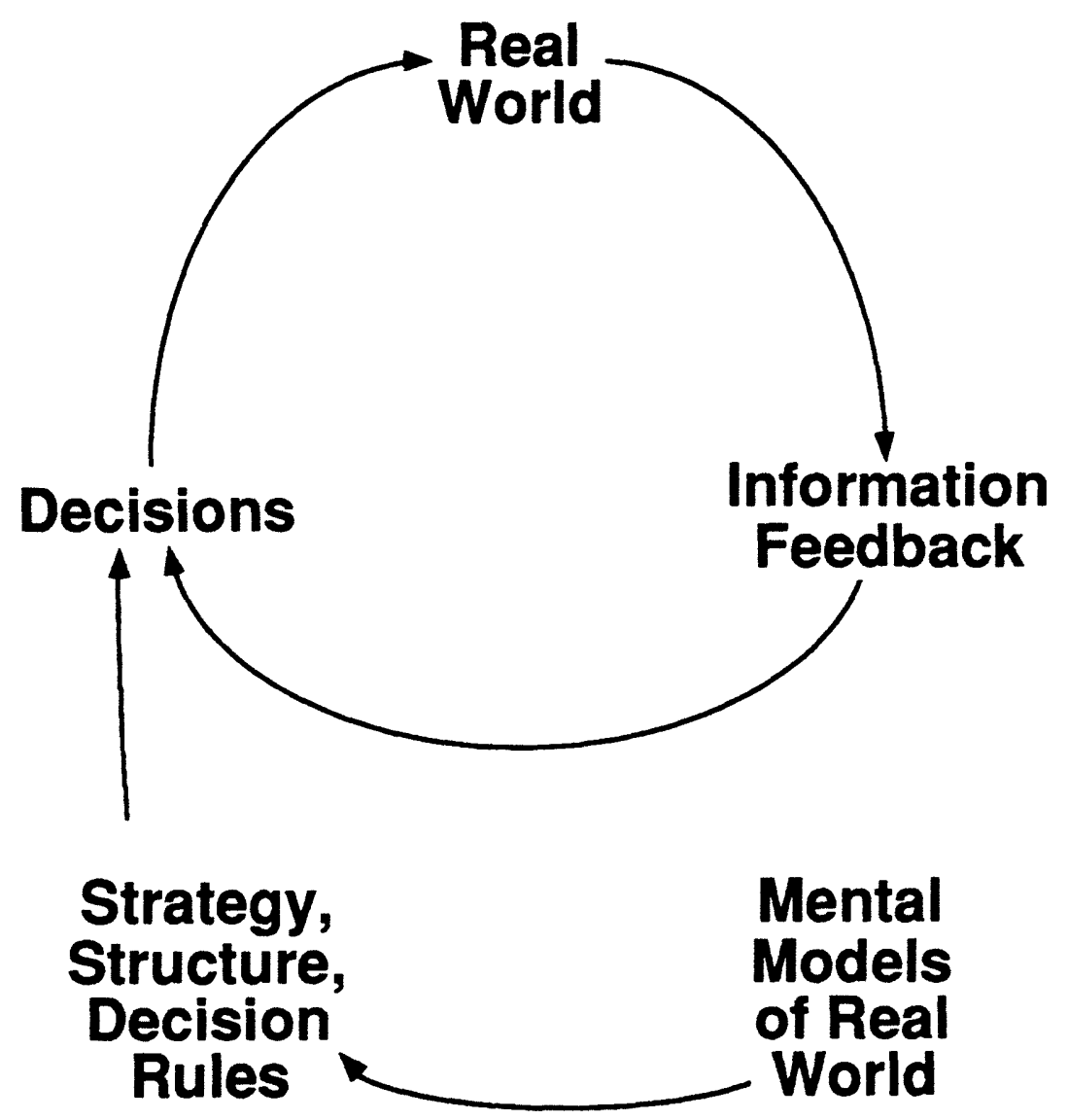



Figure 4. Diagram of a company's supply chain. Note that the time intervals do not map onto the lengths of the segments representing those intervals. The corporate goal was to reduce the duration of the supply chain by half, to roughly 90 days. The figure has been simplified compared to the actual chart to protect company -confidential information, but is drawn to scale.

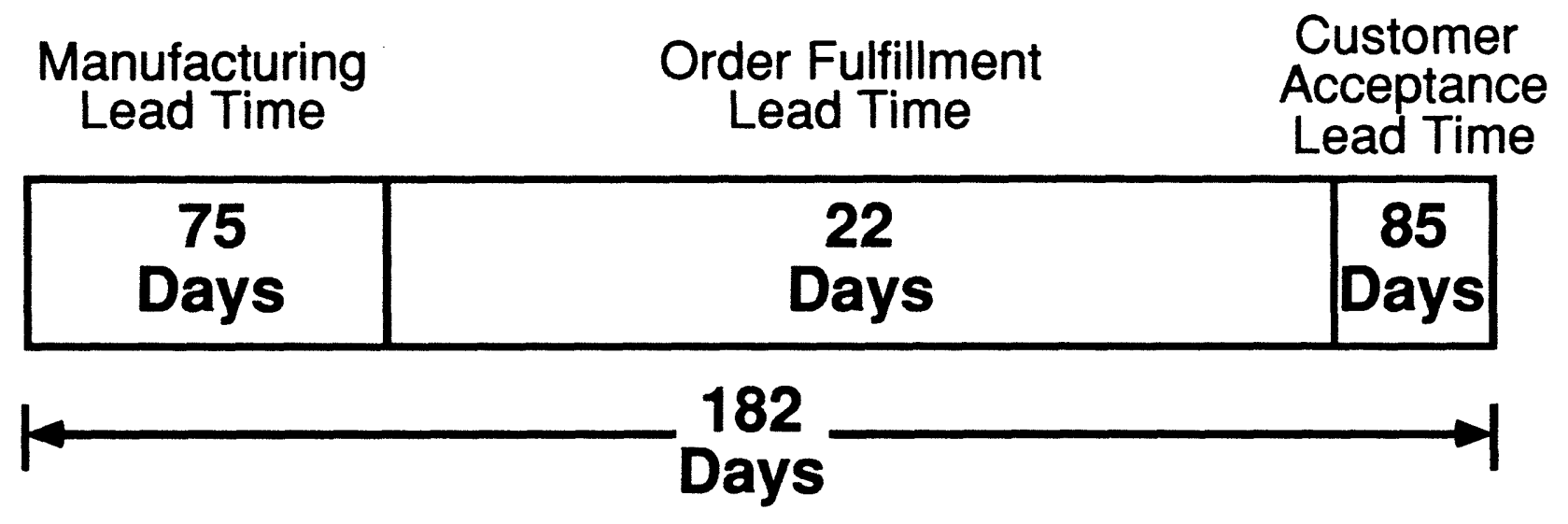


Figure 5. Feedback from the real world can also cause changes in mental models. Such learning involves new articulations of our understanding, or reframing of a situation, and leads to new goals and new decision rules, not just new decisions.

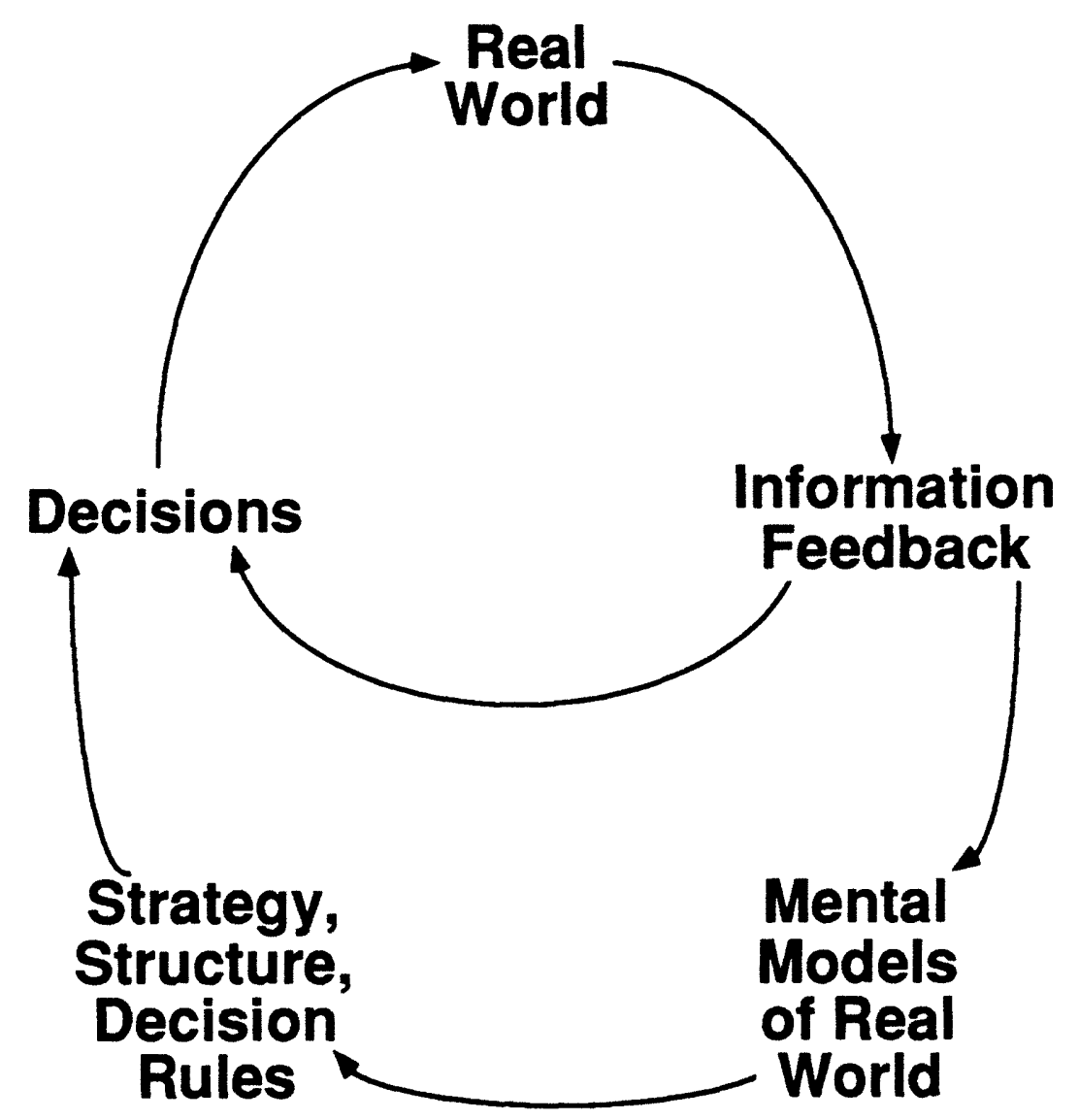


Figure 6. Impediments to learning.

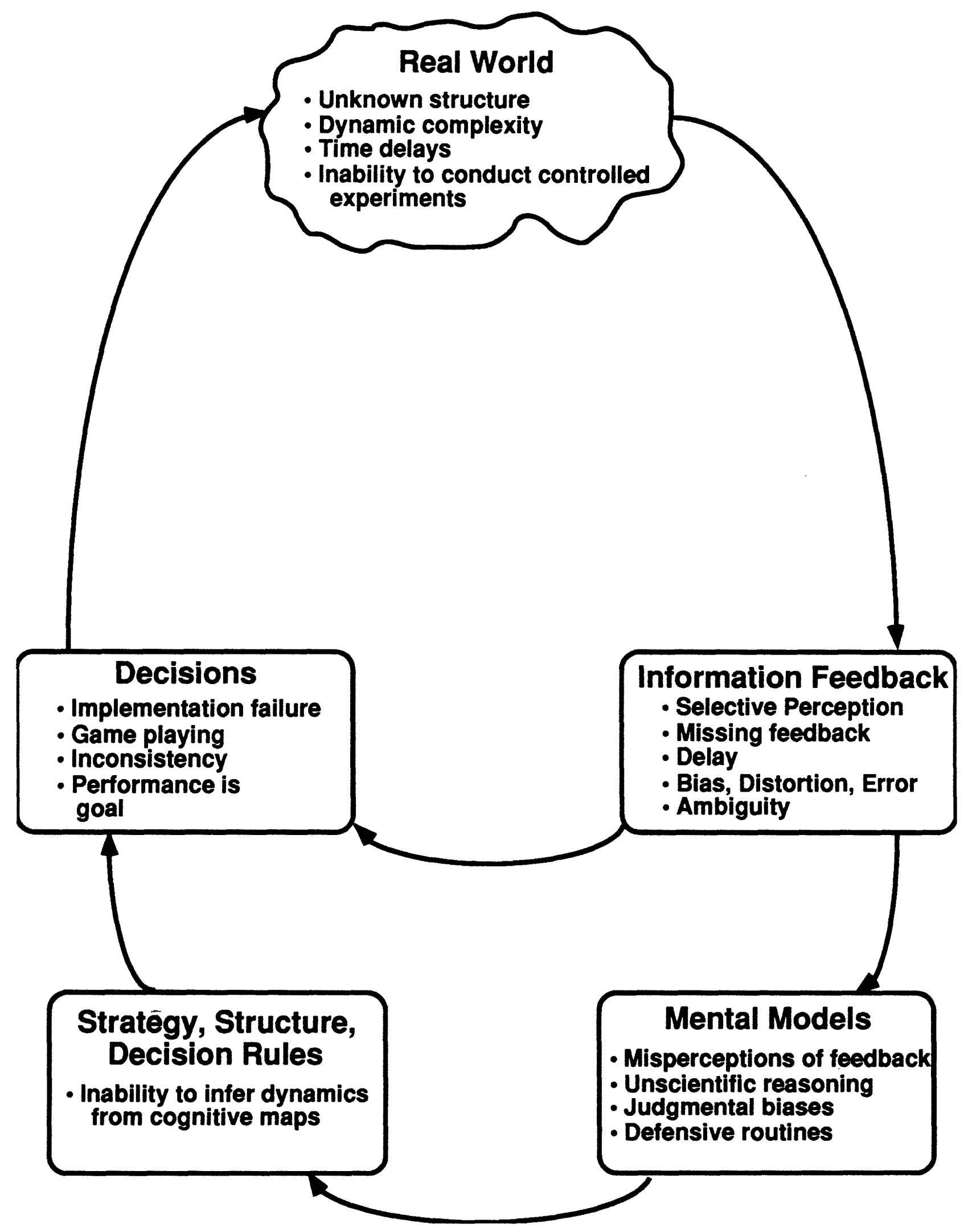


Figure 7. Wason card task. What is the smallest number of cards you should turn over to test the rule that 'cards with vowels on one side have even numbers on the reverse', and which are they?
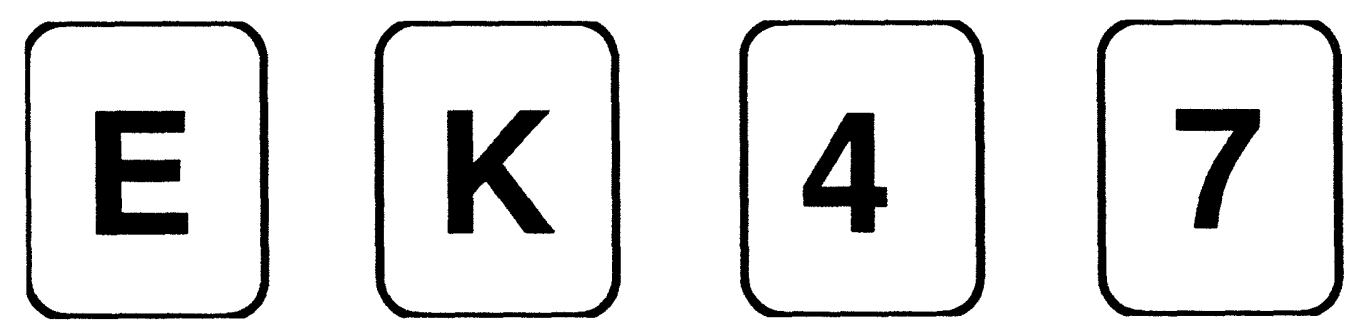
Figure 8. Idealized learning loops. Effective learning involves continuous experimentation in both the virtual world and real world, with feedback from both informing development of the mental models, the formal models, and the design of experiments for the next iteration.

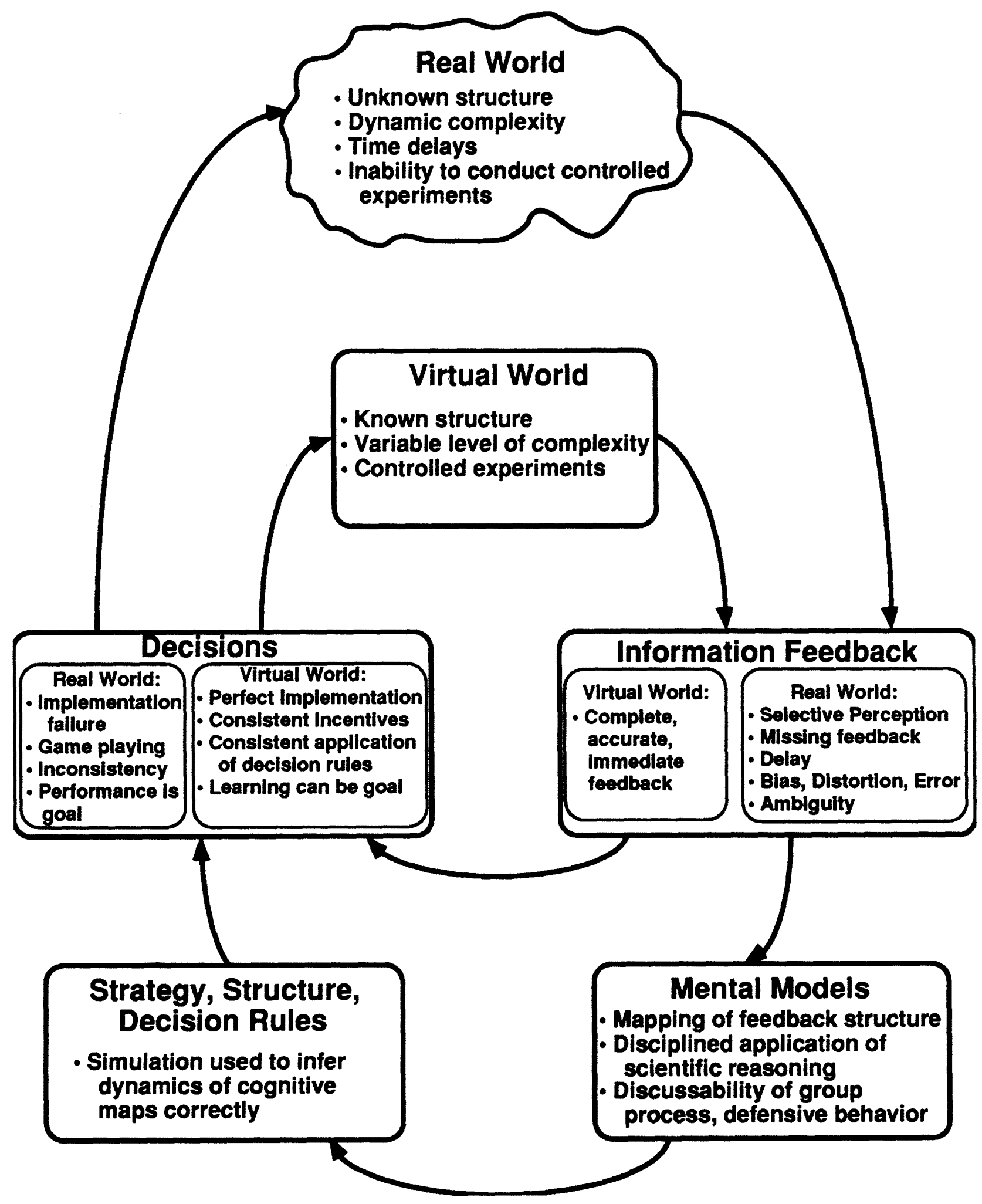

